\title{
Ecological Assessments of Community Disorder: Their Relationship to Fear of Crime and Theoretical Implications ${ }^{1}$
}

\author{
Douglas D. Perkins ${ }^{2}$
}

University of Utah

\section{Ralph B. Taylor}

Temple University

\begin{abstract}
Researchers suggest that fear of crime arises from community disorder, cues in the social and physical environment that are distinct from crime itself. Three ecological methods of measuring community disorder are presented: resident perceptions reported in surveys and on-site observations by trained raters, both aggregated to the street block level, and content analysis of crime-and disorder-related newspaper articles aggregated to the neighborhood level. Each method demonstrated adequate reliability and roughly equal ability to predict subsequent fear of crime among 412 residents of 50 blocks in 50 neighborhoods in Baltimore, MD. Pearson and partial correlations (controlling for sex, race,
\end{abstract}

\footnotetext{
${ }^{1}$ This research was supported by National Institute of Mental Health grants 1-R01-MH40842-01 and -02 from the Center for Violent and Antisocial Behavior, R.B.T., principal investigator, D.D.P., project director. R.B.T, also received support from grants IJ-CX-93-0022 and 94-IJ-CX-0018 from the National Institute of Justice during preparation of this manuscript. Opinions are solely those of the authors and do not reflect the opinions or official policies of the National Institute of Justice or the Department of Justice. This article benefitted in too many ways to list from the comments of Barbara B. Brown, Ron Davis, Marybeth Shinn, and anonymous reviewers on earlier drafts. Kenneth Maton and his students assisted in the collection of the on-site observational data. Jim Leflar and Sunil Madhugiri helped with the newspaper sampling and content analysis. D.D.P.'s students in Research Methods assisted in analyzing the interrater agreement of the newspaper content analysis procedure. Interviewing was carried out by Survey Research Associates of Baltimore.

${ }^{2}$ All correspondence should be sent to Douglas D. Perkins, Environment and Behavior Area, FCS Department, AEB, University of Utah, Salt Lake City, Utah 84112.
} 
age, and victimization) were calculated at multiple levels of analysis: individual, individual deviation from block, and community (block/neighborhood). Hierarchical linear models provided comparable results under more stringent conditions. Results linking different measures of disorder with fear, and individual and aggregated demographics with fear inform theories about fear of crime and extend research on the impact of community social and physical disorder. Implications for ecological assessment of community social and physical environments are discussed.

KEY WORDS: neighborhood social disorder; physical incivilities; newspaper content analysis; ccological assessment; fear of crime; residential blocks; HLM; multilevel analysis.

Community disorder is a broad and elusive concept, difficult to define or measure in a way that all would understand and agree with. It refers to social and physical conditions and events in a locale beyond the serious crimes that may be occurring there. These conditions and events may relate to any or all of the following: residents who are no longer able to maintain a satisfactory quality of community life; unregulated, uncivil, or rowdy behaviors observed on the street that may be associated with social conflict; a lack of investment in or supervision over a locale on the part of residents or external public and private institutions, or both; and a degeneration over time in neighborhood-based physical capital, reflected in diminishing quality and/or maintenance of both public and private property.

This article has three main objectives. The first is to present three different methods for measuring community-level ecological constructs. Indicators of community disorder may be drawn from several sources: residents themselves, on-site observations of conditions, or reports from the local media, for example. In the present paper, we present examples of each of these methods.

Our second purpose is to explore and compare each method's ability to predict residents' fear of crime. Theorists have argued for 20 years that community disorder strongly influences residents' concerns for personal safety. By comparing the relative impact of different indicators, we can learn whether the strength of the relationship depends on the type of data collected. Research in this area has tended to rely on the same source of data to measure both fear and disorder: resident surveys. Will we see weaker impacts using other indicators of disorder? 
We pursue these first two purposes using nested, or clustered, data on individuals living on different street blocks, each located in a different neighborhood. ${ }^{3}$ We are interested in both ecological and psychological dynamics. More specifically, with two of our three modes of data collection, we can examine both community- and individual-level effects. This is useful for descriptive purposes, but also has important theoretical ramifications. Sociological research on disorder and fear of crime has generally implied that the processes occur largely at the ecological or neighborhood level, or that the processes represent effects of different contexts on individuals in different locations. Psychologists are more likely to assume that individual differences (e.g., in the perception of disorder) are the primary determinants of fear.

Thus, our third objective is to contrast effects at the different levels of analysis. We hope such information can be used to further sharpen our understanding of community disorder, fear of crime, and their relationship to one another. The remainder of this introduction explains the logic linking community disorder to fear of crime and then examines research linking fear with physical environment features and media sources.

\section{The Social Relevance of Fear of Crime}

Fear of crime is a serious individual- and community-level problem in urban and suburban areas, influencing how freely people move about the places where they live (Liska, Sanchirico, \& Reed, 1988). It is concerned with people's emotional responses and feelings of vulnerability in the face of dangerous conditions or the possibility of victimization (Ferraro, 1994). It emerges as distinct from people's more cognitive perceptions of risk (Dubow, McCabe, \& Kaplan, 1979).

Crime has been identified as an important environmental stressor (Lewis \& Riger, 1986; Melnicoe, 1987; Taylor \& Shumaker, 1990). Fear may be a critical factor in the related stress process. Fear has been linked with blocklevel shifts in anxiety and depression, suggesting that in the social ecology of the street block, changes in psychological distress are interwoven with fluctuations in safety-related concerns (Taylor \& Perkins, 1994; see also Norris \& Kaniasty, 1991). Fear of crime is also linked negatively with community social and psychological ties (Liska \& Baccaglini, 1990; Perkins, Florin, Rich, Wandersman, \& Chavis, 1990; Riger, Gordon, \& LeBailly, 1981; Skogan, 1990; Steward, Perkins, \& Brown, 1995; Taylor, Gottfredson, \& Brower, 1984).

\footnotetext{
${ }^{3} \mathrm{~A}$ street block is defined as both sides of a street bounded by cross streets or a cross street and a dead end. We sometimes refer to street blocks as simply "blocks." They should not be confused with (square) census blocks.
} 


\section{Fear of Crime and Community Disorder}

\section{On the Distribution of Fear and Victimization}

Social scientists initially presumed that fear of crime and actual victimization would be closely linked (Dubow et al., 1979). This presumption foundered on two points: Fear is much more widespread than victimization and the demographic groups that are most fearful are least victimized. On the latter: Young males are victimized the most but report being the least fearful. Women and the elderly, and particularly elderly women, are especially likely to report fear (Ferraro, 1994; LaGrange \& Ferraro, 1989; Lawton \& Yaffe, 1980; Mulvey, Turro, Cutter, \& Pash, 1995; Ortega \& Myles, 1987) despite comparatively low exposure to risk (Clarke, Ekblom, Hough, \& Mayhew, 1985; Liska et al., 1988) and low victimization rates, according to official crime statistics (Balkin, 1979). The validity of crime statistics is suspect (O'Brien, 1985) and the not necessarily irrational fear felt by physically more vulnerable groups may be grounded in more serious physical, psychological, or economic consequences should victimization occur (Skogan, Cook, Antunes, \& Cook, 1978). Further, if women and elderly are less often victimized by street crime, that may be due to their fear causing them to take greater precautions, such as avoiding unsafe areas at night and other behavioral adaptations (Liska et al., 1988; Norris \& Kaniasty, 1992; Skogan \& Maxfield, 1981). But the data still suggest that there may be more to "fear of crime" than simply fear of crime (Garofalo \& Laub, 1978).

\section{Fear May Reflect Broader Conditions in the Community}

On the former point: Researchers began suggesting in the mid to late 1970 s that fear of crime was more prevalent than crime because it reflected not only victimization experienced, and indirect victimization (those crime experiences heard from friends), but they proposed that it also reflected broader conditions of disorder in the community (Garofalo \& Laub, 1978; Hunter, 1978; Lewis \& Salem, 1985; Wilson, 1975). Those who witness this disorder may conclude that the community cannot manage these problems and that external agencies are unwilling or unable to deal with them (Hunter, 1978).

\section{The Incivilities Theory of Neighborhood Decline}

To residents and visitors alike, these conditions of disorder or "incivility," both physical and social, symbolize not only a superficial neglect of the community but also an underlying breakdown in both local norms of 
behavior and formal and informal social controls (Lewis \& Maxfield, 1980; Lewis \& Salem, 1985; Perkins, Meeks \& Taylor, 1992; Skogan \& Maxfield, 1981; Taylor, 1987; Taylor \& Hale, 1986; Taylor \& Shumaker, 1990). Social incivilities include such problems as loitering youths or homeless people, rowdy behavior, drug dealing, public drunkenness, and prostitution. Physical incivilities include such environmental stimuli as litter, vandalism, vacant or dilapidated housing, abandoned cars, and unkempt lots.

Subsequently, researchers expanded the model, adding a longitudinal perspective. They suggested that increases in social and/or physical signs of incivility might not only inspire residents' fear, but might also contribute independently to neighborhood decline. They argue that if incivilities are not dealt with promptly and effectively, residents perceive more social problems in the locale and lose confidence in their neighborhood and in law enforcement's ability to prevent or control open displays of disorder, let alone more serious crime. The theory suggests that as resident fears and avoidance behaviors increase, informal social controls weaken, incivilities proliferate, potential offenders are emboldened, criminals from adjoining areas are attracted to the locale, and the downward spiral becomes selfreinforcing (Skogan, 1990). This broader theory of disorder has, for some years, strongly influenced policy changes in community policing and community crime prevention (Greene \& Taylor, 1988; Wilson \& Kelling, 1982).

\section{Resident Perceptions of Community Disorder}

Regrettably, much of the research linking signs of incivility with fear has been based solely on residents' subjective perceptions of disorder, drawn from survey responses (LaGrange, Ferraro, \& Supaneic, 1992; Lewis \& Maxfield, 1980; Lewis \& Salem, 1985; Skogan, 1990; Skogan \& Maxfield, 1981). At the neighborhood level, perceptions of disorder correlate strongly with fear, and with indicators of neighborhood structure. Skogan (1990) observed a correlation of $r=.84$ between perceived disorder and neighborhood unemployment. Hope and Hough (1988) suggested that, at the neighborhood level, fear and signs of incivility may not be conceptually separable. But another interpretation is that very high fear-disorder correlations may arise in part from the two measures, when based on resident surveys, sharing method variance. We should not draw a conclusion of construct inseparability until we have examined measures of each construct drawn from different sources. A few studies have done this, using on-site observations of block and neighborhood environments recorded by trained raters. 


\section{On-Site Observations and Levels of Analysis}

Studies employing measures based on on-site observations find linkages with fear that depend in part on the level of aggregation, and the community context. At the individual level, in both U.S. and British samples, Maxfield (1987) found observed measures of physical neighborhood decay related more strongly to fear than perceived vulnerability or victimization.

In a neighborhood-level model examining impacts of observed incivilities on a broad range of responses to disorder, including fear of crime, Taylor (1996) found direct effects in the expected direction; staying in more and fear of crime were more prevalent in neighborhoods with higher rated incivilities.

A very few studies have examined both on-site observations and resident perceptions of disorder. Taylor, Shumaker, and Gottfredson (1985) found independently rated, neighborhood-level physical and social disorder to correlate strongly with resident perceptions of disorder and fear of crime. They suggested that observed disorder might influence neighborhood fear only for neighborhoods whose future was uncertain; in extremely stable neighborhoods, and in extremely disadvantaged locales, disorder will not influence fear. In the former case, residents are buffered by their secure future; in the latter case, given other extant problems, impacts of observed incivilities become diminished through a process analogous to cognitive adaptation (Taylor \& Shumaker, 1990). In Covington and Taylor's (1991) contextual reanalysis of the Taylor, Shumaker, and Gottfredson (1985) data, neighborhood-level on-site observed incivilities significantly predicted individual-level fear. But resident perceptions of incivilities, based on individual within-neighborhood deviation scores, were the strongest predictor of fear.

From the same data used in the present study, Perkins et al. (1992) found on-site observations demonstrated high interrater reliabilities and concurrent validities, significantly predicting residents' subjective assessments after controlling for block size, race, education, and home ownership. Regression analyses showed that physical incivilities were independently linked to perceptions of social and crime-related problems.

Contrary to those studies and using a similar on-site data collection instrument but in a different city, Perkins, Wandersman, Rich, and Taylor (1993) found in a block-level analysis that resident and independent ratings of block physical incivilities were not significantly correlated. But observed environmental items correlated more strongly and consistently with five different indicators of block crime over the following year than did resident perceptions of the environment. Using those same data, 
Perkins et al. (1990) found residential street block-level fear related modestly to certain independent observer-rated incivilities (e.g., litter) and nonsignificantly to others (e.g., graffiti, dilapidated housing). They also found that resident perceptions of physical disorder correlated significantly with fear, but not after controlling for block income, residential stability, and race.

It would be reasonable to assume that the relationship between community disorder and fear increases as the level of analysis gets smaller and "closer to home." Thus, the street block should be an even more relevant context for this relationship than is the neighborhood. It may be that the block-level results of Perkins et al. (1990) were not stronger and more consistent because most of the blocks in that study were well-organized with a high degree of citizen participation in crime prevention and other activities. Similar to the argument of Taylor, Shumaker, and Gottfredson (1985), the authors suggest that the formal and informal social organization of the community may help to buffer the impact of disorder on fear. What is clear, however, is that more block-level research on community disorder and fear is warranted.

In sum, recent research suggests that on-site observations of community disorder may help us understand perceptions of crime and related community problems. But these studies are limited in several ways, even if we focus on the set of studies including on-site observations and residents' perceptions of disorder. Shortcomings of the latter group include the following.

\section{Limitations}

Only two studies examine impacts of both on-site observations and resident perceptions of disorder on fear of crime. Perkins et al. (1990) used block-aggregated data only, which fails to distinguish individual and grouplevel effects. Covington and Taylor (1991) used cross-level (contextual) analysis, but misspecification of individual-level predictors could have biased the effects observed for the contextual incivility predictor (Hauser, 1974). Because effects may vary depending upon the level of analysis, an analytic approach allowing separation of different levels of process may help illuminate the varying dynamics. None of the previous studies allow for this. Third, none of the studies allow for correlated error structures. Since most of these studies use clustered samples, using either street blocks or neighborhoods or both as a sampling unit, errors within a sampling unit may be nonindependent. Analyses have not yet allowed for this. Finally, none of the studies has yet compared environmental measures of community-level 
disorder with a measure based on content-analyzed mass communication (i.e., television, radio, newspaper, or magazine reports). In the next section we turn to the research on media and fear, then conclude with a statement of an integrated model.

\section{Fear and the News Media}

If resident perceptions of community disorder do not always match more independent and systematic ones, what else besides demography and methodology may be influencing those differences? What indirect sources of information are there about local crime and disorder? One source is of course one's neighbors, which is where theories of indirect, or "vicarious," victimization arise (Skogan \& Maxfield, 1981; Taylor \& Hale, 1986; Tyler, 1984). Another important source may be the news media. The degree to which public fears are influenced by the media, and precisely how they may be influenced, have been studied but remain open questions. Some presentations of crime in the media may even have a distancing effect on personal risk assessment (Gomme, 1988). Noting that it would be maladaptive for people to rely solely on their direct personal experience of environmental hazards, such as crime victimization, Tyler (1984) reviewed the literature on how indirect, socially transmitted information influences fear of crime. He found that people receive such information through their social networks, but that studies of naturally occurring crime-risk judgments and evaluations of media campaigns suggest that citizens do not generally accept the mass media as a source of information about personal crime risk.

That conclusion may be true for electronic media, but there is some evidence for the impact of newspapers on fear. O'Keefe and Reid-Nash (1987) found that greater attention to televised news was related to subsequent increased fear, concern, and avoidance behaviors. They found no such effects for attention to crime news in newspapers, although greater concern was related to subsequent increased readership. But most other studies have found the relationship between fear and media coverage of crime to be significant for newspapers (Jaehnig, Weaver, \& Fico, 1981; Liska \& Baccaglini, 1990; Smith, 1984; Williams \& Dickinson, 1993) and modest for television viewing (Sparks \& Ogles, 1990).

Pawson and Banks (1991) used rape reports from the two Christchurch, NZ, daily newspapers over a 5-year period and found that surveyed fear of violence extended well beyond those groups and districts that featured prominently in the newspaper reports. Although this suggests either a noneffect or overgeneralized effect of newspaper coverage, younger 
women in their sample exhibited patterns of fear that indicated that were well aware of the areas with more rape news stories.

Jaehnig et al. (1981) correlated data from a survey of community residents with content analyses of newspaper crime stories. They found that the influence of newspapers on public opinion toward crime problems increases as individuals' personal knowledge of social conditions contributing to crime decreases. Comparing two urban samples, they also found much higher fear of victimization in the city with a lower reported crime rate but almost twice as many news stories about violent crime. They suggest that newspaper crime stories cause an unreasonably high fear of violent crimes and an unreasonably low concern over property crimes.

Liska and Baccaglini (1990) content-analyzed daily newspaper crime stories to measure their effect on attitudes, beliefs, and fears about crime in 26 major U.S. cities based on National Crime Survey data. Homicide stories had the highest correlation with fear of crime but, interestingly, newspaper coverage of nonlocal crime appeared to make people feel safe by comparison, regardless of the local crime situation.

Three of the most important studies on the relationship between newspaper crime reporting and fear of crime were done in Great Britain. Ditton and Duffy (1983) did not focus on fear per se, but documented widespread bias toward sensationalism in the newspaper reporting of crime news in Scotland. They found that the press reported only $0.25 \%$ of the offenses reported to the police or heard by courts. Newspapers tended to concentrate on crimes involving violence, sex, and public disorder (i.e., those most likely to induce public fears).

Smith (1984) used a household survey in Birmingham, England, to measure responses to crime news and content-analyzed 7 months of crime stories in a daily newspaper. The majority of respondents reported learning of crime events through either electronic media or the local newspaper. Similar to Ditton and Duffy (1983), the newspaper content analysis revealed such distortions of police crime reports as giving more attention to "exciting" personal offenses than to nonviolent thefts and burglaries, which actually made up $84 \%$ of reported crimes. Smith (1984) also found that news stories tended to unjustifiably link crimes with ethnic minorities. She argued that such distortions may unrealistically increase fear of crime.

Indeed, Williams and Dickinson (1993) measured the amount of space and prominence given to crime in 10 British newspapers and found a positive correlation between a newspaper's crime coverage and its readers' level of fear. This effect held even after controlling for demographic factors, although they also found that tabloid newspapers, particularly those 
targeting a working-class readership, carried more crime reports and reported crimes more sensationally than did broadsheets. Smith (1984) concluded that fear must be studied in relation to both the urban environment and newspaper coverage of crime. By comparing impacts of newspaper coverage and other urban conditions, we can accomplish this purpose.

\section{METHODS}

\section{Overall Design}

Fifty blocks in 50 different neighborhoods throughout Baltimore City, MD, were randomly selected to participate in the 1987-1988 multimethod study. Two waves of panel survey data were collected in order to examine change in sampled individuals and neighborhoods over time and to facilitate tentative causal interpretations. Extensive data were also collected by trained, independent raters at the beginning of the study on the crime and fear-related physical environment of each block and almost $70 \%$ of the respondent households. The third source of data used in the present analyses is a 15-month archive of content-analyzed crime and disorder-related news articles from the city's major daily newspaper and a minority community newspaper. The triangulation of these diverse ecological methods helps to paint a rich portrait of the sociophysical context of each community in the study.

\section{Sample Selection}

\section{Site Characteristics}

Baltimore is a typical, large, older, Eastern U.S. city, in the midst of industrial and economic change and moderate population decline in recent decades. Its fairly high rate of serious street crime was similar to comparably sized U.S. cities during the same period. In terms of demography, Baltimore's neighborhoods, though internally homogenous, are ethnically and socioeconomically diverse. Regarding housing turnover, many of the neighborhoods are fairly stable. The relatively small scale of the neighborhoods has helped most of them organize Neighborhood Improvement Associations, many of which engage in crime prevention activities. 


\section{Neighborhood Selection ${ }^{4}$}

A probability proportionate to size (PPS) procedure was used to systematically select the 50 neighborhoods to be included in the study. First, each of the 277 Baltimore neighborhoods (as defined by Goodman and Taylor, 1983, using ecologically validated boundaries and names) was ordered geographically in a serpentine pattern from the Northwest corner of the city to the Southeast peninsula. Then, the 1980 Census was used to construct a cumulative neighborhood household population frequency. Baltimore neighborhoods vary considerably in size, but the mean neighborhood population in 1980 was 2,840. Public housing projects, high-risk apartment complexes, and the central business district were excluded due to limitations on the size of the survey sample. Thus, at best our data may only be generalized to low-rise urban residential neighborhoods of moderate density.

The neighborhood sampling interval was then determined by dividing the total household population of the 250 remaining neighborhoods by 50 , the number of neighborhoods sought. A random starting number was applied to the cumulative neighborhood population table to choose the first neighborhood. The interval was then added to that number in successive steps to determine Neighborhoods 2 through 50 .

\section{Block Sampling Procedure}

The processes of informal social control, social cohesion, and territoriality, which are intrinsic to crime and disorder prevention, are considered most salient at the street block level (Perkins et al., 1990, 1992). Block household listings from a city address (criss-cross) directory were used to conduct the random selection of one block per neighborhood with probability proportionate to size. All blocks in each of the 50 neighborhoods,

\footnotetext{
${ }^{4}$ Given a limitation of 412 survey respondents, the decision process for deriving the optimum number of blocks and neighborhoods to include in the sample was based on a difficult balance between statistical power at the aggregate level and an adequate sampling ratio of individuals per block. Several different approaches to drawing the neighborhood, block, and household sampling frame were considered, based on three criteria related to variability and inferential validity: Does the sampling procedure allow for capturing sufficient individual-level variability on the measures of interest (crime, fear, disorder, ctc.)? Are there sufficient cases per social area unit to allow us to describe and draw conclusions about blocks or neighborhoods (i.e., does it provide for meaningful contextual variables)? Does the procedure capture sufficient variability at the aggregate (block/neighborhood) level? After weighing the various tradeoffs of (a) random selection throughout neighborhoods (i.e., ignoring blocks), (b) choosing more or fewer households per block, (c) more or fewer total neighborhoods in the sample, (d) stratifying the sample, we believe the plan chosen represents the best compromise. Regarding statistical power, an $n$ of 50 blocks results in power values of .57 at alpha $=.05$ and .69 at alpha $=.1$ for 2-tailed, block-level analyses of a moderate effect size $(r=.3)$.
} 
excluding boundary streets and blocks with no usable household listings, were entered in a cumulative household population distribution. Unusable listings include businesses, offices, and addresses with more than 15 listings (i.e., generally, high-rise apartment buildings). Due to the tendency of Baltimore neighborhoods to be culturally homogenous and the exclusion of high-rise, predominantly commercial and boundary blocks, every block sampled appears to be reasonably representative of its surrounding neighborhood, physically and demographically. The representativeness of each block's physical characteristics was verified in person at the time of household sampling and environmental observation (below).

\section{Household Sampling Procedure}

For use with the survey and environmental measures, a field household enumeration on each selected block provided a more complete and up-to-date listing of households than the address directory permits. The field listing and systematic household selection were conducted at the same time as the environmental observation (below). This procedure entailed visual inspection of each address on the block for number of occupied units. Then, the interval selection of eight primary and four replacement households on each block with a random start was done on site.

\section{Survey Respondent Sample}

Of an initial sample frame of 601 potential respondents, no contacts were attempted for 13 addresses and 13 others were verified, in person, as vacant, thus leaving an $n$ of 575 attempted contact households (response rate $=72 \%$ ). If one looks only at those households in which someone was actually reached, however $(n=492)$, the completed interviews per householdcontacted response rate is $84 \%$ ( $n$ of refusals, break-offs, and language problems $=80$ ). Eligible respondents for this study were a randomly selected head of household. Within household replacements were not allowed. The final Time 1 survey sample $(n=412)$ comprised $270(65.5 \%)$ females; $52.4 \%$ were African American, $46.3 \%$ white. At the time of the survey, $17 \%$ of the sample were under 30 years of age; $54.2 \%$ were between 30 and 60 ; and $28.8 \%$ were over 60 . The mean length of residence in the current neighborhood was 14.6 years and in the respondent's current home was 12.6 years. Homeowners made up $58.5 \%$ of the sample. The mean household size is 2.9 with an average of 1 child per household. Roughly half the sample had a household income of $\$ 20,000$ or more. 
The Time 1 survey sample was used as the sampling frame for the follow-up survey conducted 1 year later. The panel sample $(n=305)$ had a response rate of $74 \%$. The two samples did not differ significantly by sex, race, or fear of crime. The Time 2 sample had a higher percentage of homeowners and long-term residents and was a mean of 3.4 years older at Time 1 . Weighting the Time 2 sample by home ownership (the most significant source of attrition bias) had very little effect on other differences between the samples, which suggests that those differences (less victimization and perceived block crime and disorder problems at Time 2) are probably due more to change than sample attrition.

\section{Instruments}

\section{Block Environmental Inventory}

The Block Environmental Inventory (Perkins et al., 1992) is a combination of the authors' previous separate research involving direct observational measurement of the crime and fear-related physical environment of urban residential blocks. The instrument was pilot-tested and refined throughout the training of six raters. Three teams of two raters each were sent to separate blocks in January 1987. Raters were not allowed to discuss a particular rule or rating as they conducted a block observation. They were, however, allowed to discuss the interpretation of a rule between blocks.

The first page (Section I) of the inventory covers the number of young men and women (approximately ages 10-35), children, and adults outdoors at a given point in time and their general activities (walking, "hanging out," etc.), abandoned cars, damaged or graffiti painted public property, types and amount of open land use (vacant lots, church or school yards, parking lots, playgrounds, gardens, etc.), and whether the land is poorly maintained. Although there is undoubtedly variation in people's use of outdoor space by time of day, environmental data collection was limited to 5:00 to 8:00 p.m. on weeknights and noon to 8:00 on weekends. A more serious limitation in the present area is that they were collected in winter when people spend less time outdoors. Thus, the restriction of the variables time and weather may also restrict the influence of the independent variable "males outdoors."

For the second page (Sections II, III, and IV), the raters start over at the beginning of the block, walk down one side of the street at a time, keeping a count of the number of occupied residential units. Each nonresidential (stores, schools, etc.) and mixed-use building was rated for litter 
in front of it, vandalism (e.g., graffiti, broken windows), and lack of exterior maintenance (peeling paint, broken fixtures) (block-level $\alpha=.76$ ). The eight primary survey sample households were selected (see Household Sampling Procedure, above) and rated for litter, vandalism, and lack of exterior maintenance (block-level $\alpha=.73$ ). (See Appendix A.)

Interrater reliability, or agreement, has been a problem for many observational measures. Table I presents means, standard deviations, and interrater reliability coefficients for the inventory. Five blocks were rated by only one rater and so were excluded from these analyses. With the exception of a few, low base-rate items, such as young males engaged in "other" outdoor activities, abandoned cars, and trash-filled empty lots, interrater agreement for block-level observations was high (mean intraclass correlation ( $\mathrm{ICr}=.78)$. Interrater reliabilities were consistently high for property-level observations. The $\mathrm{ICr}$ for recognizing the number of abandoned buildings on a block is .92. Section III covers each nonresidential property on a block. Its mean reliability coefficient for all items is $\mathrm{IC} r=.86$. Section IV consists of 16 items on eight sample homes per block. These may be aggregated to the block level, which renders higher reliability coefficients than at the property level. Block-level ICrs for the three disorder items range from .67 to .83 with an overall mean (including nondisorder items) of .81. See Perkins et al. (1992) for psychometric information on the entire instrument.

\section{Survey of Residents}

Beginning 2 weeks after the environmental data collection, eight residents on each study block were interviewed in late winter, 1987 (Time 1), and again 1 year later (Time 2). The survey took approximately 35 minutes to complete. If the respondent could not be interviewed by telephone, an interviewer was sent door-to-door to try to conduct the survey. Of the 412 interviews completed in Time 1, $191(46 \%)$ were by telephone and 221 were in person.

The overall survey was designed to elicit residents' perceptions of the quality of the surrounding social and physical environment, the extent of residents' social support resources - including both the format and informal network of neighbors helping neighbors, their behavioral and emotional responses to crime and victimization, and the stressful impact of persistent fear on residents' mental health status. 
Table I. Disorder Items in the Block Environmental Inventory: Means and Interrater Reliability ${ }^{a}$

\begin{tabular}{|c|c|c|c|c|}
\hline & $M$ & $S D$ & $\begin{array}{c}\text { Intraclass } \\
r\end{array}$ & \\
\hline \multicolumn{5}{|l|}{ Section I: Block-level characteristics } \\
\hline Males, 10-35, observed outdoors hanging out & 0.36 & 1.70 & .83 & \\
\hline Walking & 0.64 & 1.10 & .84 & \\
\hline Working & 0.16 & 0.76 & .91 & \\
\hline Other & 0.05 & 0.25 & -.02 & \\
\hline Total males, $10-35$ & 1.21 & 2.10 & .85 & \\
\hline Unused vacant lots as estimated $\%$ of block & 0.64 & 1.72 & .97 & \\
\hline Open lot lack of maintenance & 0.24 & 0.37 & .43 & \\
\hline Number of abandoned cars on street & 0.31 & 0.83 & .53 & \\
\hline \multicolumn{5}{|l|}{ Section II. All properties (per block) } \\
\hline Total abandoned building & 1.4 & 2.2 & .92 & \\
\hline \multicolumn{5}{|l|}{ Section III. All nonresidential properties } \\
\hline Total vacant nonresidential units & 0.14 & 0.43 & .86 & \\
\hline Litter on/in front of nonresid. property & 0.39 & 0.92 & .82 & \\
\hline Vandalism/graffiti on nonresid. property & 0.27 & 0.71 & .92 & \\
\hline \multirow[t]{2}{*}{ Nonresidential dilapidation } & 0.44 & 1.0 & .90 & \\
\hline & & & $\begin{array}{l}\text { Household- } \\
\text { level }\end{array}$ & $\begin{array}{c}\text { Block- } \\
\text { level }\end{array}$ \\
\hline Section IV. Sample homes & $M$ & $S D$ & IC $r$ & $\mathrm{IC} r$ \\
\hline Physical Disorder Subscale & & & .69 & \\
\hline Litter in front of house & 0.44 & 0.29 & .61 & .83 \\
\hline Vandalism/graffiti & 0.10 & 0.14 & .47 & .67 \\
\hline Dilapidated exterior & 0.47 & 0.27 & .53 & .71 \\
\hline
\end{tabular}

${ }^{a}$ See Perkins et al. (1992) for an explanation of the entire instrument. The $n$ of blocks is 45 . The $n$ of properties in Section IV is 365.

The present analyses use only the survey measures of demographic variables and perceptions of social and physical environmental disorder and crime problems from Time 1 and fear of crime from Time 2. Although a variety of demographic questions were asked, the ones used here are those that have been empirically linked with fear (i.e., sex, age, and race). The fourth covariate for the present analyses is criminal victimization in "past 12 months." A series of items prompted the type of crime attempted, whether it happened more than once, whether any attempts were successful, whether any attempts occurred within two blocks of home, and whether the incident was reported to the police (adapted from the National Crime Survey and Perkins et al., 1993). 
Residents assessed crime and fear-related block problems on a 3-point scale (i.e., a big problem, somewhat of a problem, or not a problem) used in other community surveys (e.g., Perkins et al., 1990). The internal consistency of the total scale is alpha $=.88$. The present analyses use just two subscales (based on unit-weighted, $z$-scored items) derived by factor analysis. One is perceived physical disorder: "vandalism, like people breaking windows or spray painting buildings," "vacant housing," "people who don't keep up their property or yards," "litter or trash in the streets," and "vacant lots with trash or junk" (individual-level $\alpha=.75$; block-level $\alpha=.87$ ). The other subscale is perceived social disorder: "people who say insulting things or bother other people when they walk down the street," "groups of teenagers hanging out in the street," "people fighting or arguing," "people selling illegal drugs" (individual-level $\alpha=.80$; block-level $\alpha=.89$ ). We used hierarchical linear modeling (HLM) to assess how much residents on a block agreed with one another on these indices (Bryk \& Raudenbush, 1992, p. 63). The way HLM handles intraclass agreement is in terms of estimated true group means as a function of how much members of each group agree with each other, how far the block mean is from the grand mean, and how large the group is. The overall reliability of the block means on perceived social disorder was .775; the overall reliability of the block means on perceived physical disorder was .684 . These substantial reliability coefficients indicate that the observed block means are quite acceptable as indicators of the true block means on these indices.

Fear of crime is measured with a series of questions on felt and perceived safety of self and household members, in the neighborhood and on the block, adapted from several studies, including Greenberg, Rohe, and Williams (1982), Rosenbaum, Lewis, and Grant (1986), and Taylor et al. (1984) (see also Ferraro \& LaGrange, 1987). Based on principal components analysis at the individual level, three subscales were obtained: emotional fear, worry, and comparative (geographic and temporal) risk perceptions. For the present analyses, we use the emotional component, which consists of six questions: 1) "How safe would you feel being out alone on your block during the day?" (2) The same question is then asked about how the respondent would feel "elsewhere in your neighborhood" and ( 3 and 4$)$ both of those questions are again asked for "at night." The response categories for those four items were collapsed in order to be comparable to the other two dichotomous items in the emotional fear scale. (5) "Would you be afraid if a stranger stopped you at night in your neighborhood to ask for directions?" and (6) "Would you feel uneasy if you heard footsteps behind you at night in your neighborhood?" The internal consistency of the scale at the individual level and prior to collapsing is alpha $=.82$. Block level (intrablock agreement) reliability was an acceptable .77 , indicating the observed block means adequately capture the true block means. 


\section{Baltimore Newspaper Archive}

Two Baltimore newspapers were reviewed, abstracted, and coded into an archival database for the purpose of accounting for the potential fearrelated influence on survey respondents of local crime and disorder news coverage between the two waves of survey data (i.e., to monitor potential "history" threats to statistical conclusion validity). The Baltimore Sun is the largest daily newspaper in the area. Sampling strategy is critical to validity but often overlooked in content analysis (Babbie, 1995). Thus, the semiweekly Baltimore Afro-American was also used to offset any bias in favor of Sun coverage of predominantly white neighborhoods: $73.5 \%$ of the 321 articles selected were taken from the Sun and the rest were from the AfroAmerican.

Four research assistants were trained to skim and identify relevant articles in weekday issues of the Sun (those most likely to contain relevant articles) and all issues of the Afro-American from January 1, 1987, to March 31, 1988. The type of articles which were abstracted covered two general topics: Approximately $80 \%$ were reports of events expected to influence crime-related attitudes in, or in neighborhoods adjacent to, one or more study neighborhoods. These included articles reporting specific crimes, social or physical disorder problems, or the immediate community response to specific crime-related problems. Articles on "disorder" include the physical deterioration of housing or other property, racial unrest, and prison escapes or unrest. Both kinds of articles were expected to influence perceptions of personal vulnerability, attitudes toward the city's ability to reduce crime, and possibly anticrime behaviors of residents in study neighborhoods. They provided the basic sampling element, aggregated to the neighborhood level, for the present analyses. The rest of the archive included news stories about criminal justice system or community development (e.g., housing and urban planning) programs or policy changes. Articles on events occurring in unsampled neighborhoods (including all public housing projects) and surrounding counties were ignored unless they were adjacent to at least one sampled study neighborhood.

Due to the inclusion of articles on incidents either in or near study neighborhoods, there were many cases (articles) relating to more than one neighborhood of interest. For each event, we allowed for up to four possible neighborhoods that the event is in or near. (Obviously, unless an incident occurs on a neighborhood boundary as happened on two occasions, it can only be "in" one neighborhood, but it can be "near" three). With regard to data processing, all of the information was entered into a database and all but the lengthy text article title and summary fields 
were also exported for statistical analysis. This allowed us to summarize all the relevant and available news for each neighborhood by having the program sort through data and select if any one of the four neighborhood codes equalled the target neighborhood code. The result was a separate list of news events and issues occurring in or near each neighborhood.

One issue that arose was how to handle multiple articles on a single incident. Our purpose here was not to estimate the amount of actual crime but the amount of print media coverage of social disorder and related matters in the sample neighborhoods. Thus, a general rule we used was to discard a follow-up story to an incident if it only covered criminal justice system responses that were deemed inconsequential to community fear. We did include follow-up stories that discussed new information on an event, such as community reaction or an arrest, and both articles on the same event in each newspaper. Thus, the frequencies or means of "crimes" in the archive actually refers to different news reports of crimes, or "articlecrimes," two or more of which may be on the same incident. Hence, as the British studies of crime news show, the more sensational the crime such as a particularly brutal murder, kidnapping, or rape - the more coverage it receives and the greater it is (in effect) weighted in the present scheme. Again, we believe this is appropriate for a measure of media's expected impact on fear.

Just over $50 \%$ of the crime stories included a homicide as one of the crimes mentioned. The next most frequently mentioned crimes were, respectively, assault, robbery and weapons offenses, burglary, drug dealing, and rape. Use of a deadly weapon was reported in $70 \%$ of all crime stories. Multiple crimes occurring during the same incident were reported in $35 \%$ of the crime articles. The average number of people injured was 1.4. Excluding those articles that were unclear on the exact number, the average number of offenders was 1.6, although this may be an underestimate as accomplices were not always mentioned in a news story.

The number of articles in a particular neighborhood ranged from $0(n=22)$ to 20 . The number of articles near a given neighborhood ranged from $0(n=6)$ to 54 . Several examples clearly demonstrated the importance of noting crimes not only within the neighborhood's boundaries but also in adjacent neighborhoods. Many had few or even no article-crimes within them but many nearby. There were only 4 study neighborhoods in which no incidents or policy issues (i.e., no articles) were located in or near them. All are smaller neighborhoods located near the outer edges of the city. 
No interrater reliability information is available for this data set. But the same coding form was used by 17 minimally trained undergraduate raters content analyzing issues of the Salt Lake Tribune and the Deseret News. Six articles were selected by only one or two of nine raters (per issue). The other 10 articles were selected by a range of 33 to $89 \%$ and a mean of $59 \%$ of the raters. If one considers all articles on which a decision was made (including those rejected by all raters), selection agreement would be over $95 \%$. Furthermore, raters of the newspapers used in the following analyses received much more training and experience with the procedure. Even so, article selection reliability deserves caution in the present study and closer scrutiny in rater training and future research.

Scores for pairs of raters on the Salt Lake news data were cross-tabulated. The kappa coefficients (agreement corrected for chance) were as follows: type of crime ( 26 possible categories; $\kappa=.72$ ), policy issue (12 categories; $\kappa=.21$ ), use of a weapon (yes/no; $\kappa=.77$ ), number injured $(\kappa=.87)$, number of offenders $(\kappa=1.00)$. With the main focus on crime articles, the baseline for selecting relevant policy-related articles and for assigning policy issues to all articles was low. This may be the reason that the kappa for that variable was not higher. In many cases, raters identified a policy issue where others saw none. But in the 7 cases where a pair of raters both identified a policy issue, the raters agreed on what the issue was in every case.

\section{Approach to Data Analysis}

\section{Variables}

To recapitulate the variables to be used in the present analyses, disorder items have been combined within all three of the above methods into social and physical composite independent variables. From the Block Environmental Inventory, we used three measures of observed disorder: The proportion (based on the number of housing units on the block) of young men outdoors is a possible cue for perceived social disorder. We aggregated the property-level items to the block level and combined the three home physical disorder (litter, vandalism, and dilapidation) into a scale. Since nonresidential property has been found to be a significant magnet for crime (Perkins et al., 1993) and disorder (Taylor et al., 1995), we combined three inventory items: (a) poorly maintained open land use, (b) the proportion of nonresidential buildings with graffiti and (c) with dilapidated exteriors into nonresidential physical disorder. 
From the newspaper archive, we combined all stories about homicides, rapes, assaults, robberies, and burglaries into one serious crime news variable (neighborhood $M=14.04, S D=17.99$ ). Articles about other crimes were less common. We combined all stories that mentioned other nontraffic offenses (e.g., carrying a weapon, drug abuse, car theft, kidnapping, domestic disturbance, arson, prostitution, vandalism, and disorderly conduct incidents) into a disorder crime news variable (often referred to as "quality-of-life crimes"; neighborhood $M=4.72, S D=7.98$ ). The third variable of interest are stories on the physical deterioration of housing or other property, racial unrest, and prison escapes or unrest, which we labeled disorder news (neighborhood $M=0.26, S D=0.66$ ). As the standard deviations imply, all three of these variables have fairly skewed distributions, with most neighborhoods having few relevant newspaper stories and a few neighborhoods with many. All three variables were aggregated to the neighborhood level (sum of stories) and each story was weighted according to whether the event or problem took place near $(=1)$ or in $(=2)$ the target neighborhood.

We used the Time 1 resident survey, aggregated to the block level, for the demographic (sex, age, race) covariates and to combine loitering youths, harassment in the street, fights and arguments, and drug dealing into perceived social disorder and vandalism, vacant housing, unkempt property, litter, and trashed vacant lots into perceived physical disorder. We used the aggregated Time 2 survey for the criminal victimization (in the past year) covariate and the emotional subscale of fear of crime. Fear, the dependent variable, was thus measured 12 to 15 months after the observational and survey predictors and at the end of a year measuring victimization and crime-and-disorder-related news.

\section{Analyses}

First, we present correlations among fear, the key exogenous variables (sex, race, age, and criminal victimization), and the various measures of disorder. We also examine correlations after partialing those same exogenous variables. These correlations are analyzed at the individual level, the individual-within-block level (i.e., using pooled group variance), and the aggregate community level. For this level and for the analyses below, community is defined as the residential street block for the environmental and survey data and the neighborhood for the news data. We briefly discuss a multiple regression analysis of the data. Finally, we analyze three hierarchical 
linear models of the multilevel impact of disorder on fear. These analyses allow us to test a multilevel model of the impacts of community disorder on fear of crime. Before describing the multilevel model we explain how HLM operates (see Appendix B for more details).

Significance tests are two-tailed for correlation matrices and onetailed for predictors in the HLMs. Given the number of blocks and neighborhoods in the study ( $n=50$ ), the degrees of freedom, and thus statistical power, are rather limited, especially for multivariate analyses. Kenny and LaVoie (1985) recommended raising the significance criterion to $p<.25$ when analyzing (more reliable) group-level data. (All of these community-level variables are based on multiple survey respondents, properties, or newspaper articles.) Instead, for just the HLM, we adopt a significance level of $p<.10$ for Level II hypothesis tests, which yields an acceptable degree of statistical power.

\section{Relevant Features of Hierarchical Linear Modeling}

HLM represents a family of models specifically devoted to analyzing hierarchical data where individuals are nested within larger units such as students in schools (Bryk \& Raudenbush, 1992; Bryk \& Thum, 1989). They also have been applied to changes in individuals over time (Bryk \& Raudenbush, 1987; Raudenbush \& Chan, 1992, 1993). Combining maximum likelihood and empirical Bayes estimation techniques they separate out between-group from within-group effects, provide estimated true scores of group means, generate empirical Bayes estimates of predictor slopes within each group, and allow cross-level interactions to be explored by permitting varying slopes for individual predictors across groups, and examining the group-level determinants of those varying slopes. HLM takes into consideration the assumption that residuals (error) within groups are correlated.

For our purposes here the following HLM advantages are pertinent. (a) We can gauge the amount of variation in fear of crime that is due to differences between communities. This is useful descriptive information. (b) We can test whether the between-community variation is significantly greater than zero. (c) After entering our community-level predictors, we can see how much of the between-community variation in fear they explain, and test whether significant between-community variation remains. (d) HLM uses precision weighting and empirical Bayes (EB) estimates of group means. Therefore data quality is taken into account across communities, 
and at that level we are not predicting observed means, but rather EB estimates of "true" community means..$^{5}$ (e) HLM makes assumptions about correlated within-group errors that are more appropriate to the clustered data we have than are the assumptions about error made by ordinary least squares (OLS). (f) We can simultaneously explore individual-level effects on the dependent variable. The impacts of these individual-level, or Level I, predictors are completely independent of the community level (II) impacts because we center each Level I predictor by its group mean. Thus each Level I predictor tells us about the contrast between the individual and the block mean, pooled across blocks.

In HLM it is possible to explore interactions between individual and context by allowing slopes of Level I predictors to vary across groups. We did not do this because of data limitations (see Appendix B) and because of insufficiently developed theoretical rationales.

\section{Model to Be Tested in HLM}

In HLM we test the models described below to predict fear of crime. We enter exogenous variables at theoretically appropriate levels (individual or block) and as the data permit. In contrast to contextual analysis, exclusion of a variable at one level does not bias the coefficients or the standard errors at the other level.

Victimization is entered at Level II. Blocks where more residents report victimization are likely to be blocks where street and/or property crime are higher. Controlling for block victimization helps us roughly control for the amount of crime occurring on the block. It was not possible to control for victimization at the individual level because on several blocks no respondents reported victimization.

\footnotetext{
${ }^{5}$ More specifically, HLM considers: size of the Level II groups (i.e., number of Level I units in each Level II unit), distance of each Level II observed mean from the estimated true grand mean, and how much respondents in each Level II unit agree with each other on the attribute in question. As a reviewer has pointed out, there are other sources of data quality variation across Level II units. But the critical point here is that many different sources of "error," including misinterpretations of questions by some respondents or varying interviewer effects, will contribute to one of the above three factors that are taken into account in HLM precision weighting.

${ }^{6} \mathrm{~A}$ reviewer has reminded us that HLM cannot test a multistep causal model. It seems plausible to argue that community conditions give rise to perceptions of community conditions, and that the latter influence fear. So the impact of observed, on site, disorderly conditions may be mediated by the perceptions of those conditions. HLM cannot test such a model. But as Covington and Taylor (1991) have shown, observed, on-site conditions have unmediated, direct impacts on fear, separate from the impacts of perceived conditions. So if that model was not seriously misspecified, we know that perceptions and on-site conditions each have their own independent, direct impacts on fear. It is those that we test in the HLM models here.
} 
Race. Residents on more predominantly African American blocks, all else equal, are likely to receive less aggressive police action and other services (Taylor \& Covington, 1993). Skogan and Maxfield (1981) suggested that minorities are more fearful because race captures an ecological vulnerability to disorder. Race is thus entered at the block level. We are unable to enter race at the individual level because on several blocks all respondents were either white or African American. (Given the strong Level II correlations between racial composition and disorder indicators, we ran each analysis twice, once with race included, and once with it excluded. Results were closely comparable, yielding no substantive differences. We show the results here with race included.)

Age. At the individual level, residents who are older than their neighbors may feel less integrated into the block social life and may even be intimidated by being surrounded by younger residents. They may not know the teens hanging out on the block as the teens' parents probably do. At the block level, age may link with fear for two possible reasons. Skogan and Maxfield (1981) suggested older residents are more fearful because they are more physically vulnerable. On a block of predominantly elderly residents, this may translate to a collective sensing itself to be vulnerable and lacking adequate informal social controls. As a group, they may participate less in outdoor activities on the block. A dearth of adult residents viewed outside may render daily events on the block less familiar and more threatening to all residents, not just the elderly.

Gender. Sampson (1987) has argued that female-headed households in an urban locale may predominate because of joblessness and the associated lack of stable males. The problems stem not from the female-headed households per se, but rather from the associated unemployment and related male instability in the locale. His argument, originally specific to urban black communities, seems appropriate to other urban residential locations as well. Thus, gender at the block level serves as a proxy for block stability. We were unable to enter gender at Level I because on some blocks all respondents were women.

Disorder. We enter three disorder measures at the individual level. One is physical disorder (litter, vandalism, dilapidation) independently observed at the respondent's home. Disorder theory predicts that those keeping their place up less than their neighbors are less interested in their neighborhood, more alienated from neighbors, and thus more fearful. But this anticipated effect may not emerge at this level for two reasons: First, physical upkeep in many locations is the responsibility of landlords as well as residents. Second, residents are likely to be concerned about their neighbors' upkeep (the Level II effect: see below), but incivilities on one's own property may be fear-provoking only if one believes that others are directly responsible for it (e.g., gang graffiti). 
The other two disorder measures at Level I are perceived social disorder and perceived physical disorder from the resident survey. Those seeing more problems than their neighbors on the same block should be more fearful than their neighbors. Those seeing the block as more problem-ridden may spend more time there or may just be more sensitive to the block context because of differential adaptation processes (Taylor \& Shumaker, 1990).

The Level II predictors of community disorder will vary depending upon the specific model. In the observed disorder model we will enter mean block scores for observed home physical disorder, nonresidential disorder, and number of young men outdoors. We expect each to contribute positively to mean block fear. With regard to the last of these three measures, we do not mean to imply that all young men observed outdoors are, or should be, viewed by either residents or raters as a threat or a symbol of disorder. We are merely using it as an admittedly crude proxy for the presence of a potential source of youthful incivilities. It may also reflect relative levels of joblessness, or nearby amenities that draw foot traffic but at the same time destabilize the block setting (Taylor et al., 1995).

In the perceived disorder model we enter block means for perceived physical disorder and perceived social disorder. We expect block residents' shared views of physical and social problems to each contribute independently to their level of fear.

Finally, in the newspaper model, we enter neighborhood-level aggregates for disorder crime news and disorder news. Each neighborhood corresponds to a different block in the sample. As explained below in the multiple regression analysis, serious crime news correlated highly with disorder crime news and so was excluded from the HLM analyses. We expect that media attention to nearby quality-of-life crimes and disorder problems will each contribute independently to block fear.

\section{Summary}

We have described above the specific hypotheses to be tested for Level I and Level II predictors. Level I results tell us about pooled effects of differences of individuals from their block average (on perceived social and physical disorder and one measure of observed disorder). Level II results tell us about block and neighborhood-level effects. In the first equation we include measures of observed disorder, based on block-level and aggregated property-level ratings. This model tells us whether, in addition to psychological 
processes at Level I, ecological processes are also at work at the block level. In the second equation we include two measures of perceived disorder, based on block mean survey responses. In the third equation we include measures of disorder crime news and noncriminal disorder-related news, based on content-analyzed newspaper articles aggregated to the neighborhood level. These last two models tell us whether, in addition to the Level I psychological processes, social psychological processes involving group perceptions and/or mass communications are also simultaneously at work at Level II.

\section{RESULTS}

\section{Correlations Among Fear, Demographics, Victimization, and Community Disorder}

Table II presents unadjusted correlations among fear of crime, demographics, criminal victimization experienced in the year preceding the fear measure, and community disorder. These correlations represent combined between-person and between-block dynamics. Above the diagonal are partial correlations controlling for sex, race, age, and victimization. Women and African Americans were more fearful. Resident perceptions of block social and physical disorder were significantly, and about equally, related to fear. On-site observations of the respondent's own property showed only a trend with fear. It is not surprising that this trend was nonsignificant since it is disorder in the rest of the community rather than one's own home, that is expected to be associated with fear of street (as opposed to domestic) crime.

Table III presents individual-level correlations among the same variables as in Table II, based on pooled, within-block deviations. All variables are block-centered. Again, partial correlations, controlling for block-centered sex, race, age, and victimization, appear above the diagonal. These correlations capture solely individual-level processes. Sex was still significant, indicating that women living on blocks that were more predominantly male (based on the gender ratio of those we interviewed) were especially fearful. (An alternative explanation would be that men living on blocks with more women were less fearful.)

The disorder measures also emerged significant, this time including on-site observations as well as perceived incivilities. Those who were most fearful not only perceived more disorder on the block than their neighbors; they also lived on properties with objectively more physical disorder (litter, graffiti, dilapidation) than was observed on their neighbors' homes. 
Table II. Individual-Level Zero-Order Correlations Among Fear of Crime, Demographics, Victimization, and Community Disorder; Partial Correlations (Above Diagonal) Controlling for Sex, Race, Age, and Victimization

\begin{tabular}{ccccccccccc}
\hline & $n$ & 1 & 2 & 3 & 4 & 5 & 6 & 7 & 8 \\
\hline 1. Fear of crime & $a$ & 300 & - & & & & & .14 & $.22^{c}$ & $.21^{c}$
\end{tabular}

Control variables
2. Female
$412 \quad .27^{c}-$
3. Nonwhite
4. Age
5. Victimization ${ }^{a}$
$410 \quad .15^{b} \quad .13^{b} \quad-$
$\begin{array}{llll}303 & .13 & .00 & -.04\end{array}$
$\begin{array}{llllll}305 & .11 & -.01 & -.08 & -.13 & -\end{array}$

Independent observation of respondent's property
6. Physical disorder
$283 \quad .16 \quad-.01$
$\begin{array}{lllll}.28^{c} & -.12 & .15 & -\quad .36^{c} \quad .28^{c}\end{array}$

Surveyed resident perceptions

$\begin{array}{llllllllll}\text { 7. Social disorder } & 411 & .25^{c} & .05 & .14^{b} & -.09 & .26^{c} & .41^{c} & - & .65^{c} \\ \text { 8. Physical disorder } & 412 & .25^{c} & .07 & .19^{c} & -.02 & .13 & .33^{c} & .67^{c} & -\end{array}$

${ }^{a}$ Fear of crime and victimization were measured 1 year later than the other variables. ${ }^{b} p<.05$, two-tailed.

${ }^{c} p<.01$, two-tailed.

Table III. Correlations Among Individual-Level Block-Deviation Scores for Fear of Crime, Demographics, Victimization, and Community Disorder; Partial Correlations (Above Diagonal) Controlling for Sex, Race, Age, and Victimization

\begin{tabular}{|c|c|c|c|c|c|c|c|c|c|}
\hline & $n$ & 1 & 2 & 3 & 4 & 5 & 6 & 7 & 8 \\
\hline 1. Fear of crime ${ }^{a}$ & 300 & - & & & & & $.19^{b}$ & $.26^{c}$ & $.17^{b}$ \\
\hline
\end{tabular}

Control variables

$\begin{array}{llrrrrrr}\text { 2. Female } & 412 & .28^{c} & - & & & \\ \text { 3. Nonwhite } & 410 & -.07 & .02 & - & & \\ \text { 4. Age } & 303 & .06 & -.02 & -.17^{b} & - & \\ \text { 5. Victimization } & { }^{a} & 305 & .09 & -.00 & -.08 & -.11 & -\end{array}$

Independent observation of respondent's property
6. Physical disorder
$283 \quad .17^{b}-.05$
$\begin{array}{lllll}.09 & -.09 & -.15 & - & .38^{c}\end{array}$
$.39^{c}$

Surveyed resident perceptions

$\begin{array}{llllllllll}\text { 7. Social disorder } & 411 & .27^{c} & .04 & -.08 & -.04 & .22^{c} & .39^{c} & - & .65^{c} \\ \text { 8. Physical disorder } & 412 & .20^{c} & .08 & -.10 & .02 & .10 & .38^{c} & .66^{c} & -\end{array}$

${ }^{a}$ Fear of crime and victimization were measured 1 year later than the other variables. ${ }^{b} p<.05$, two-tailed.

${ }^{c} p<.01$, two-tailed. 
Table IV contains block-level correlations among fear of crime, demographics, crime (victimization rate), and all three measures of disorder. Again, partial correlations controlling for proportion female, racial composition, mean age, and crime appear above the diagonal. These correlations capture purely block level dynamics. Fear was higher on blocks with higher proportions of women $(r=.34, p<.05)$ or African American interviewees $(r=.45, p<.01)$. Fear of crime was also significantly related to all of the measures of community disorder across all three methods. The largest partial correlations (controlling for sex, race, age, and victimization during the 12 months between surveys) were for the on-site observation measures, especially physical disorder around nonresidential property $(\mathrm{p} r=.38, p<.01)$. The number of young males outdoors $(\mathrm{p} r=.31$, $p<.05)$ and litter, graffiti, and dilapidation around homes $(\mathrm{p} r=.32$, $p<.05)$ also predicted block fear a year later.

Surveyed resident perceptions of physical disorder problems $(r=.41$, $p<.01 ; \mathrm{p} r=.25, p<.05)$ and social disorder problems $(r=.37$, $p<.01 ; \mathrm{p} r=.21, p<.10)$ also predicted block fear a year later, although the effect was reduced noticeably after controlling for demographics and victimization.

Neighborhood-level noncrime newspaper stories about social or physical disorder problems were related to fear of crime $(r=.34, p<.05$; $\mathrm{p} r=.28 ; p<.05$ ). That result may not be completely reliable, however, due to the low frequency of such articles $(n=9)$. Disorder crime news was also related to fear $(r=.41, p<.01 ; \mathrm{p} r=.24, p<.10)$. But the correlation between fear and serious crime news was even more sharply reduced by controlling for race and the other covariates $(r=.38, p<.01$; $\mathrm{p} r=.16, \mathrm{~ns})$.

\section{Multiple Regression Analysis}

A block-level hierarchical multiple regression using all three types of disorder measures was tested. Block racial and sex composition were entered first followed by the three observational measures, the two resident perception variables, and the three newspaper predictors $\left(R^{2}=.45\right.$, adjusted $\left.R^{2}=.31, p<.005\right)$. Due to the higher degree of multicollinearity even across these very different measures of disorder (i.e., what one would hope for in terms of construct validity), reversed valence suppression effects (positive correlations/negative betas) were found for serious crime news, resident perceptions of social incivilities, and disorder crime news. 
Table IV. Community-Level Correlations Among Fear of Crime, Demographics, Victimization, and Three Measures of Community Disorder; Partial Correlations (Above Diagonal) Controlling for Sex, Race, Age, and Victimization ${ }^{a}$

\begin{tabular}{|c|c|c|c|c|c|c|c|c|c|c|c|c|c|}
\hline & 1 & 2 & 3 & 4 & 5 & 6 & 7 & 8 & 9 & 10 & 11 & 12 & 13 \\
\hline 1. Mean fear of crime ${ }^{b}$ & - & & & & & $.32^{c}$ & $.38^{d}$ & $.31^{c}$ & .21 & $.25^{c}$ & .16 & .24 & $.28^{c}$ \\
\hline \multicolumn{14}{|l|}{ Control variables } \\
\hline 2. Proportion female & $.34^{c}$ & - & & & & & & & & & & & \\
\hline 3. Proportion nonwhite & $.45^{d}$ & $.35^{c}$ & - & & & & & & & & & & \\
\hline 4. Mean age & .04 & .17 & .12 & - & & & & & & & & & \\
\hline 5. Mean victimization ${ }^{b}$ & .04 & -.13 & -.07 & -.23 & - & & & & & & & & \\
\hline \multicolumn{14}{|l|}{ Independent observations } \\
\hline 6. Home physical disorder & $.45^{d}$ & .07 & $.47^{d}$ & -14 & .21 & - & $.39^{d}$ & .16 & $.61^{d}$ & $.66^{d}$ & $.48^{d}$ & $.49^{d}$ & .23 \\
\hline 7. Nonresidential property physical disorder & $.36^{d}$ & -.13 & .16 & -.05 & .12 & $.44^{d}$ & - & $.54^{d}$ & $.42^{d}$ & $.28^{c}$ & $.53^{d}$ & $.59^{d}$ & $.58^{d}$ \\
\hline 8. Young men outdoors & $.32^{c}$ & -.16 & $36^{d}$ & -.13 & -.11 & $.32^{c}$ & $.55^{d}$ & - & $.35^{d}$ & .07 & $.38^{d}$ & $.50^{d}$ & $.41^{d}$ \\
\hline \multicolumn{14}{|l|}{ Surveyed resident perceptions } \\
\hline 9. Mean social disorder & $.37^{d}$ & .11 & $.41^{d}$ & -.20 & .23 & $.72^{d}$ & $.45^{d}$ & $.41^{d}$ & - & $.73^{d}$ & $.49^{d}$ & $.41^{d}$ & $.25^{c}$ \\
\hline 10. Mean physical disorder & $.41^{d}$ & .12 & $.43^{d}$ & -.12 & .26 & $.76^{d}$ & $.34^{c}$ & .20 & $.80^{d}$ & - & $.58^{d}$ & $.42^{d}$ & .16 \\
\hline \multicolumn{14}{|l|}{ Newspaper articles } \\
\hline 11. Serious crime news & $.38^{d}$ & .17 & $.62^{d}$ & .14 & .00 & $.60^{d}$ & $.51^{d}$ & $.48^{d}$ & $.56^{d}$ & $.65^{d}$ & - & $.84^{d}$ & $.39^{d}$ \\
\hline 12. Disorder crime news & $.41^{d}$ & .18 & $.48^{d}$ & .02 & .09 & $.61^{d}$ & $.58^{d}$ & $.53^{d}$ & $.53^{d}$ & $.55^{d}$ & $.87^{d}$ & - & $.58^{d}$ \\
\hline 13. Disorder news & $.34^{c}$ & .12 & .23 & .12 & -.11 & .27 & $.55^{d}$ & $.40^{d}$ & .26 & .20 & $.44^{d}$ & $.59^{d}$ & - \\
\hline
\end{tabular}

${ }^{a}$ All data aggregated to block level except news data (Nos. 11-13), which were aggregated to the neighborhood-level; $N$ of blocks/neighborhoods $=$ 50; partial correlation $d f=44$.

${ }^{b}$ Fear of crime and victimization were measured 1 year later than the other variables.

${ }^{c} p<.05$, two-tailed.

${ }^{d} p<.01$, two-tailed. 
The remaining multivariate analyses thus tested separately each of the three methods of measuring community social disorder for its ability to predict fear of crime. In a regression with only demographic and news predictors, the beta was negative for serious crime news, which correlated highly with both the proportion nonwhite and disorder crime news. We therefore excluded serious crime news from the following HLM analyses. This also makes the focus on disorder, as distinct from serious crime, more consistent across all three methods.

\section{Hierarchical Linear Models Predicting Fear of Crime}

ANOVA. An initial HLM, with no Level I or Level II predictors describes the between- and within-group variation; it is comparable to a one-way ANOVA. We are able to reject the null hypothesis that there is no betweenblock variation in estimated fear true scores $\left(\chi^{2}=93.11, p<.001\right)$; $17 \%$ of the total variance in fear arises from between-block variation. Table $V$ shows the variance results of the ANOVA, and subsequent models. The amount of between-block variance in fear is comparable to or somewhat larger than what has been observed in other studies. Kurtz and Taylor (1995), analyzing fear levels across 66 neighborhoods in Baltimore, found that $15 \%$ of fear was due to between-neighborhood variation. Reanalyzing surveys from residents surrounding 24 small commercial centers in Minneapolis-St. Paul, Taylor (1995) found that $4 \%$ of the variation from a neighborhood fear index, and $8 \%$ of the variation from a more specific index measuring fear while in the commercial center, arose from between-neighborhood differences. In this study we assess between-block rather than between-neighborhood differences, and this may account for a greater proportion of the outcome variance residing at Level II. Alternately, the higher proportion may be due to the smaller group sizes used here than in these other studies.

Observed Disorder. The variance results for each of three different models including both Level I (individual within-block deviations) and Level II (block-level) predictors appear in Table V. In the observed disorder model, our Level II predictors (including aggregate race, age, sex, victimization rate, both home and nonresidential exterior physical disorder and young men observed outdoors on the block) explain $37.8 \%$ of the block-level outcome variation, and $6.4 \%$ of the total variation. ${ }^{7}$ Sig-

\footnotetext{
${ }^{7}$ Unlike OLS, HLM does not allow one to determine if the addition of specific predictors results in improved fit. This can only be done when the fixed predictors are held constant, and a random effect is added, and you compare two deviance statistics. With different models and different predictors, as is the case here, we only can gauge if the remaining, unexplained variation at Level II is significant.
} 
nificant unexplained block-level variation in the outcome remains $\left(\chi^{2}=68.47, p<.01\right)$. Individual coefficients in the model appear in Table VI. Level I effects remain constant for all three models. The only significant Level I impacts are associated with perceived disorder. Residents who perceive more social and physical disorders than their neighbors report more fear 1 year later. Individual differences in age, and observed residential deterioration, make no independent contributions to individual-level differences in fear. Turning to Level II results, we first examine the observed disorder model. Three Level II predictors yield significant demographic impacts. Fear is higher on blocks where the average age was higher, where more women were interviewed, and where nonresidential physical disorder was more extensive. Level II predictors were $z$ scored, allowing us to compare coefficients. The largest Level II coefficient is for the proportion of women interviewed on the block.

Perceived Disorder. When we use resident perceptions of disorder for our Level II indicators of incivility, we explain about the same amount of fear: $7.2 \%$ of total fear, and $42.3 \%$ of between-block fear. Again, the chisquare test informs us that significant, between-block variation in fear remains $\left(\chi^{2}=69.72, p<.01\right)$. In the Level II predictors, average age and the proportion of women remain significant. Average perceived physical problems significantly influence block fear, and generate the strongest Level II coefficient. This latter result, considered in conjunction with the Level I impact of perceived physical disorder, demonstrates two channels of influence on fear. Not only are those perceiving more problems more fearful than their neighbors; in addition, on blocks where the average perceived physical problems are higher, residents are more fearful. Of course, as mentioned earlier, because of data properties, we cannot say if this independent, Level II impact would persist if we controlled for observed disorder.

Newspaper Reports. Results using news reports of so-called quality-oflife, or disorder, crimes and of noncriminal disorder problems, aggregated to the neighborhood level, yield comparable amounts of explained variance. Now our Level II predictors explain $7.6 \%$ of the total outcome variation and $44.7 \%$ of the between-group variation. Again, significant, unexplained between-group outcome variance remains $\left(\chi^{2}=67.79, p<.01\right)$. At Level II, disorder news demonstrates a significant coefficient $(.166, p<.05)$. Average age and proportion female continue to have significant impacts. In this model, racial composition also has a significant impact on fear, with fear being higher on blocks where more African Americans were interviewed. 
Table V. Hierarchical Linear Modeling Analyses of Residual and Explained Variation in Fear of Crime ${ }^{a}$

Observed disorder

Perceived disorder

Newspapers

\section{Model}

\begin{tabular}{|c|c|c|c|c|c|c|c|c|}
\hline \multirow[b]{2}{*}{ Location of variance } & \multicolumn{2}{|c|}{ No predictors } & \multicolumn{2}{|c|}{ Observed disorder } & \multicolumn{2}{|c|}{ Perceived disorder } & \multicolumn{2}{|c|}{ Newspaper reports } \\
\hline & Variance & $\%$ of total & Variance & $\%$ of total & Variance & $\%$ of total & Variance & $\%$ of total \\
\hline & \multicolumn{8}{|c|}{ Residual variation } \\
\hline Between blocks & 0.148 & 17.0 & 0.092 & 10.6 & 0.085 & 9.8 & 0.082 & 9.4 \\
\hline Within blocks & 0.723 & 83.0 & 0.671 & 77.1 & 0.681 & 78.2 & 0.673 & 77.3 \\
\hline Total & 0.871 & & & & & & & \\
\hline$\chi^{2}$ & 93.11 & $p<.001$ & 68.47 & $p<.01$ & 69.72 & $p<.01$ & 67.79 & $p<.01$ \\
\hline
\end{tabular}

$\%$ Between

$\%$ Total

Explained between-block variation

$37.8 \quad 6.4$

$\begin{array}{ll}37.8 & 6.4 \\ 42.3 & 7.2 \\ 44.7 & 7.6\end{array}$

${ }^{a}$ Due to strong Level II correlations between racial composition and disorder indicators, each model was analyzed two ways: with and without race. Results here for explained between-block variation include the race variable. The top portion of table describes between- and within-block variation. "No predictor" model is equivalent to a one-way ANOVA, and provides a descriptive breakdown on the total outcome variance. Remaining portions of the top panel describe how much unexplained variance remains at each level, after predictors have been entered. So the between-block residual variation in the observed disorder model is 0.092 ; this represents $10.6 \%$ of the total outcome variance. What has been explained is $(0.148-0.092)$ or 0.056. This explained variation, as shown in the bottom panel, represents $37.8 \%$ of the between block outcome variation, and $6.4 \%$ of the total outcome variation. In other words, the bottom panel describes the explained variance as a percentage of between variance, and as a percentage of total variance. The chi-square values indicate, for each of the models, if the amount of between-block outcome variance remaining after Level II predictors have been entered, is significantly different from zero. The chi-square associated with "no predictors" tells us if the between-block variation, before predictors are entered, is significantly different from zero. 
Table VI. Coefficients of Level I and Level II Predictors in Three HLM Models of Disorder Predicting Fear of Crime

\begin{tabular}{|c|c|c|c|}
\hline \multirow[b]{2}{*}{ Predictor } & \multicolumn{3}{|c|}{ Model } \\
\hline & $\begin{array}{l}\text { Observed } \\
\text { disorder }\end{array}$ & $\begin{array}{c}\text { Perceived } \\
\text { disorder }\end{array}$ & $\begin{array}{c}\text { Newspaper } \\
\text { reports }\end{array}$ \\
\hline \multicolumn{4}{|l|}{ Level II (Street block) } \\
\hline Mean victimization & .026 & .007 & .031 \\
\hline Proportion nonwhite & .065 & .075 & $.117^{d}$ \\
\hline Mean age & $.134^{e}$ & $.136^{e}$ & $.109^{d}$ \\
\hline Proportion female & $.205^{e}$ & $.179^{f}$ & $.155^{e}$ \\
\hline Home physical disorders & .066 & - & - \\
\hline Nonresidential property physical disorder & $.163^{d}$ & - & - \\
\hline Young men outdoors & .114 & - & - \\
\hline Mean perceived social disorder & - & -.071 & - \\
\hline Mean perceived physical disorder & - & $.228^{e}$ & - \\
\hline Disorder crime news ${ }^{a}$ & - & - & .088 \\
\hline Disorder news $^{a}$ & - & - & $.166^{e}$ \\
\hline \multicolumn{4}{|l|}{ Level I (Individual) } \\
\hline $\mathrm{Age}^{b}$ & .079 & .079 & .079 \\
\hline Home physical disorder ${ }^{b}$ & -.009 & -.009 & -.009 \\
\hline Perceived social disorder ${ }^{b}$ & $.214^{e}$ & $.214^{e}$ & $.214^{e}$ \\
\hline Perceived physical disorder ${ }^{b}$ & $.289^{e}$ & $.289^{e}$ & $.289^{e}$ \\
\hline $\mathrm{EB}$ Intercept ${ }^{c}$ & -.165 & -.089 & -.115 \\
\hline
\end{tabular}

${ }^{a}$ News data collected for entire neighborhood within which a given block is located.

${ }^{b}$ Group-mean centered predictor.

${ }^{c}$ The EB intercept is comparable to the intercept (A) OLS multiple regression, except that it uses precision weighting and adjusts for data quality. All predictors are $z$-scored, so coefficients can be compared for their relative size.

${ }^{d} p<.10$, one-tailed.

${ }^{e} p<.05$, one-tailed.

$f_{p}<.01$, one-tailed.

\section{DISCUSSION}

\section{Summary and Implications}

We presented three very different ecological methods for assessing community-level social and physical disorder problems: the Block Environmental Inventory based on systematic observations, aggregated subjective perceptions from a survey of residents, and a procedure for content-analysis of newspaper articles. The criterion-related validity of all three was demonstrated by their roughly equal ability to predict subsequent fear of crime, 
even after controlling for the influence of variables that have been linked with fear in the research literature (race, sex, age, and victimization). In each HLM model, one Level II indicator demonstrated a significant effect. The differences between the three models were minor, in part because two thirds of the Level II predictors were the same. Each explained about 6 to $8 \%$ of the total variation in estimated "true" fear scores.

These results provide some confirmation of existing theories (Skogan, 1990; Taylor, 1987; Wilson \& Kelling, 1982), but also extend earlier research on the impact of community social and physical disorder (Covington \& Taylor, 1991; Perkins et al., 1990, 1992, 1993; Taylor \& Covington, 1993; Taylor, Shumaker, \& Gottfredson, 1985). For example, as expected, women were significantly more fearful of crime in both the correlational and HLM analyses. But we found this result not only at the individual level but also at the block-centered individual level and the block level. This shows the importance of community context (e.g., being surrounded by more men than women on one's block) even for variables that seem exclusively individualistic, such as sex. The block-centered individual-level result suggests that having more men as neighbors tends to induce fear, rather than reduce it (e.g., through a greater sense of block protection). This finding replicates Taylor et al.'s (1984) finding also using pooled within-block measures. An alternate interpretation of the block-level result is that the proportion of women may serve as a proxy for block instability and associated lack of employment opportunities (Sampson, 1987).

The effect of age on fear is less clear in these results. The fact that it was only significant as a Level II HLM predictor is an example of a multilevel result that was not found in individual or even group-level correlations. Mean block age is only a significant predictor of fear after controlling for other block and individual-level variables.

With regard to racial composition, the significant block-level correlation between fear and the proportion of nonwhite respondents on the block in the present data confirms previous studies (Taylor et al., 1984). What is interesting here is that when we control for disorder in the HLM models using observed ratings, or respondents' perceptions, racial composition does not have a significant impact on fear. This is because the Level II correlation between racial composition and disorder news $(r=.23)$ is weaker than the correlation between racial composition and the other disorder indicators (mean $r=.42$ ). This weaker correlation argues against those contending that media sources tend to highlight and overemphasize physical problems occurring in predominantly African American communities. 
In interpreting the HLM model for observed disorder, we see that disorder around the home and young men outdoors matter less than disorder on nonresidential property, which makes an independent contribution to block fear. The effect may arise from the physical blight itself or from the presence of nonresidential land uses, such as stores and small businesses, that are the site of the disorder. Nonresidential land use in a predominantly residential context contributes to a more deteriorated and less predictable block (Taylor et al., 1995).

The results for this model build on and clarify previous findings on the impact of observed disorder on fear of crime. Unlike Perkins et al. (1990), the present results control for block-level sex, age, and victimization and individual-level within-block deviations in perceived disorder.

Covington and Taylor (1991) accounted for those and other factors at either the individual or contextual level. But the present model extends their findings in several ways. First, Covington and Taylor (1991) used one combined, individual-level scale composed largely of perceived physical incivilities. Results here show that both social and physical perceived disorder can make independent, individual-level contributions to fear of crime. Second, results here suggest that nonresidential deterioration may contribute more to fear than residential deterioration. The prior study did not separate those two types. Third, in that study the unit of aggregation was the neighborhood. The relative impact of (individual-level) perceived disorder to (neighborhood-level) observed disorder was on the order of $3 / 1$. In this study, using the street block as the aggregation unit and standardized predictors, we get individual coefficients of comparable size when we compare observed versus perceived deterioration.

The results of this study make several important contributions. First, we have shown that resident perceptions of disorder contribute to fear at both the individual and aggregate levels. Community-level effects may emerge from residents having common perceptions of the surrounding physical and social milieu and/or communicating with one another about that milieu. Further research is needed to determine the relative influence of shared information versus independent, common perceptions on community fear level. But the very high correlations found here between resident perceptions and independently observed physical disorder (see Table IV) suggest that the disorder theory of fear does not depend on perceptions being spread or exaggerated via communication among neighbors (cf., Crenson, 1983; Taylor, 1996).

Second, we found the effects of perceived disorder and observed disorder on fear to be significant 1 year later. 
Third, we distinguish between social and physical disorder and found that, although both correlate with fear, physical disorder had higher blocklevel and individual-level HLM coefficients than did social disorder, and this effect was triangulated using all three assessment methods. Thus, litter, graffiti, and dilapidation may be more likely to induce feelings of vulnerability than do "groups of teenagers hanging out," perhaps because the latter are less common. Still, this effect is somewhat surprising given that the social disorder measures in the survey and news data included actual quality-of-life crime items (e.g., drug dealing, menacing, public disturbance), which should logically provoke more fear.

Fourth, in particular, we found that, although people often complain about unkempt housing exteriors, nonresidential physical disorder may contribute more to fear of crime. We do not know if the problem is the presence of nonresidential land uses per se, which can destabilize the block setting (Taylor et al., 1995), or the deterioration on the establishments.

Fifth, in comparison to Covington and Taylor (1992), these results demonstrate that the residential street block is at least as valid an ecological unit of analysis when considering disorder and fear as are neighborhoods. We observed strong block-level reliabilities for perceived disorder and fear.

Sixth, and perhaps most important, this study is the first we know of explicitly contrasting the relative impacts of three different ecological methods of assessing community disorder. We have seen that, controlling for age, race, gender, and victimization experience, all three measures perform about the same, yielding comparably sized coefficients. There are no marked differences in the proportions of Level II variance explained. Our perceived physical disorder measure yields a larger coefficient than the other indicators, but the differences are minor. The safest conclusion may be that each type of assessment yields roughly comparable measures of impact (see Choosing Methods, below).

Turning briefly to our exogenous variables, results confirm Level II but not Level I impacts of age. These results differ from prior contextual analyses (Covington \& Taylor, 1991), and are relevant to the ongoing debate about the linkage between fear and age (LaGrange \& Ferraro, 1989). We need more theoretical attention to the relevant processes, at the appropriate level, that might be responsible for these impacts. We failed to observe effects of block racial composition. Some prior studies using neighborhoods have observed such effects (Covington \& Taylor, 1991), others have not. Prior block-level analyses have observed racial composition impacts on fear (Taylor et al., 1984). The emergence of a significant Level II race impact when we use neighborhood-level, media indicators of disorder rather than 
block-level indicators, suggests the following. Prior block studies may have observed race composition impacts because race and disorder correlate at the block level. In short, impacts of race at the block level may have emerged because race served as a proxy for signs of incivility. The consistent impact of gender suggests further attention. Small group studies in the residential context have not attended closely to aggregate impacts of female-headed households. Theoretical development building on the neighborhood dynamics described by Sampson (1987), and considering their application to smaller residential units, may prove profitable.

Finally, our results have something to say about fear of crime and the ongoing debate about its construct validity (Ferraro, 1994; LaGrange \& Ferraro, 1989). As described above, theorists have turned to noncriminal causes of fear to explain its apparent lack of connection to criminal victimization (which, again, was not a significant predictor of fear in this study and even the correlation between serious crime news and fear was nonsignificant after controlling for block racial composition). They have focused instead on the unsettling conditions, alternately labeled sources of "urban unease," "signs of incivility," "soft crimes," or something else, which residents may encounter. Results here inform these proposals in two respects. First, they confirm that the proposed connection has underpinnings in psychological differences. Residents on the same block, although they may and do view it differently, experience the same physical and social setting. Their differences in how they perceive that setting make them more or less concerned about safety than their neighbors. Second, they confirm that the proposed connection also has ecological underpinnings. Communities with differing levels of disorder express varying fear levels.

\section{Strengths and Limitations of These Methods and Results}

The sheer combination of multiple, diverse methods for assessing a community context (i.e., data triangulation) is a major advantage. That is particularly true when it comes to contexts such as crime and disorder, whose measurement has had notorious validity problems (O'Brien, 1985). Independent observations of community disorder were related not only to fear but also to resident-surveyed perceptions of disorder and to crime and disorder news stories (see Tables II, III, and IV; see also Perkins et al., 1992), thus exhibiting good concurrent validity.

The internal consistency and interrater reliability of both the resident survey scales and the Block Environmental Inventory were tested and found to be more than adequate. The reliability of the newspaper article selection 
and content analysis methodology was demonstrated using the same procedure, but with other raters and newspapers. More applications and psychometric work using two or more of the methods are recommended. In particular, it would be useful to know more about survey respondents' exposure to specific environmental and media stimuli.

\section{Choosing Methods}

If the measures are about equally predictive, one might question the need to ever use more than one measure (e.g., surveyed perceptions). Other studies, using different measures with different items and different samples may obtain different results, however. Furthermore, a separate and still unresolved issue concerns the construct validity of each of these assessment procedures. The various methods may still be measuring different underlying processes. For example, group perceptions reflect a mix of group attitudes, group communication patterns, and extant conditions. On-site observations come closer to extant conditions. Further, from a policy perspective, different foci may be relevant to different goals. Community policing initiatives have concentrated on improving extant conditions (Greene \& Taylor, 1988), making on-site observations the preferred indicator. But policy-makers more concerned with distress expressed by resident groups might rather focus on the perceived disorder as their problem indicator.

Observational methods and media analyses both deserve more attention among community researchers. Their significant independent relationships with fear in the present study are noteworthy, given the advantages surveyed perceptions had. Most important, neither the Block Environmental Inventory nor the newspaper data shared method variance with the criterion as did the survey. The observational data were collected earlier than the other two methods, and more than a year before the second survey, when the criterion was measured. Only one of the three observational predictors, home physical disorder, even shares household-level sampling variance with the fear measure, again unlike the survey. The newspaper archive had the disadvantage of focusing on a larger unit of analysis altogether, the neighborhood as opposed to street block (i.e., it depends on selected residents and blocks being representative of their wider neighborhood). Most of the newspaper stories did have the advantages of being closer in time to the fear measure and being more focused on crime per se, compared to the other two methods. 


\section{Remaining Questions}

Although the present results help clarify the theoretical links between community disorder and fear, several important related questions remain. First, it is still possible that the individual-level connection between perceived disorder and fear is spurious, arising from other psychological factors. For example, people who are more worry- or anxiety-prone may be more fearful and also (inaccurately) perceive more disorder in their environment. The fact that resident perceptions of the block environment agreed closely with independent observations in this study (Perkins et al., 1992) tends to discount that explanation, however.

At the group level, although all three HLM models suggest that the conditions most troubling to residents are physical rather than social disorder, questions remain before dismissing social incivilities as a source of problems. We did find that perceived social incivilities failed to have an independent impact on fear, but they also correlated very strongly with perceived physical problems $(r=.80)$. This close coupling makes the assessment of independent impacts difficult if not impossible. Take, for example, the significant impact of nonresidential disorder on fear. The sheer presence of street-corner groceries, bars, or schools inevitably attracts nonresidents to the area, disrupts informal social controls, and makes for less safe neighborhoods (Greenberg et al., 1982; Taylor et al., 1995). So although our results seem to suggest that fear of crime is in large part fear of litter, graffiti, ${ }^{8}$ and living in a deteriorated block or neighborhood, the intertwining of social and physical disorder cautions against such a conclusion at this time.

There are many potential moderators of the impact of community disorder on fear that were not controlled for in these results. The amount of citizen participation in individual and collective crime prevention and other local organizational activity, and the nature of that participation, are likely to affect fear at both the individual and community levels (Perkins et al., 1990; Taylor \& Perkins, 1994). What we know less about is precisely how various formal and informal communication processes operate to influence perceptions of crime and disorder within communities. For example, does information about local crimes disseminated through newspapers or community meetings increase fear directly? Or do most residents hear secondhand

\footnotetext{
${ }^{8}$ It should be acknowledged that although we include graffiti as a form of physical disorder, it is also a crime. Indeed, respondents whose homes have been "tagged" with graffiti may be especially, and understandably, fearful of gang violence.
} 
accounts which may be exaggerated? And how can information about crimes be presented so that it encourages awareness and a healthy and effective response but not fear and paranoia? More information is needed about residents' exposure to various forms of communication and their reactions to each form before we can answer these questions. We would argue that ecological, multilevel analyses of actual communities are more likely than laboratory experiments to produce externally valid answers.

Although that is the approach we have taken here, we still cannot generalize to settings beyond urban, predominantly residential blocks of low-to-moderate density. We do not know if our results would hold for commercial blocks or public or high-rise housing, where patterns of communication and the use, territorial functioning, and even the definition of public space may differ dramatically.

Those types of land use also have a worse reputation for crime than do lower density, private residential blocks. Yet an important caveat to the present results is the apparently high degree of serious, violent crimes that happened to occur during the study in study neighborhoods, according to the newspaper archive. Probably the biggest crime story of the year was a series of unexplained murders of women in the Northwest section of the city. Police maintained that the crimes were unrelated, but the brutality of the attacks (most of them involving rapes and strangulation or multiple stabbings), as well as their timing (leading right up to the Time 2 survey) and accompanying warnings in the press for women not to walk alone at night and to avoid dimly lit areas suggest that female survey respondents in those neighborhoods may well have been affected by the news coverage.

There were also several, singular incidents that received considerable attention from both the media and the community. The one receiving perhaps the most attention was the murder of an 11-year-old girl and subsequent community crime prevention efforts in one of the study neighborhoods. Other major crime news incidents occurring in just a few of the study neighborhoods included the arrest and trial of two men who had executed five people in a drug-related incident, the murder of a woman and slashing of her mother and rape of her child, the robbery and critical wounding of an off-duty policeman, the bow-and-arrow slaying of a pregnant woman, the rape-murder of a 15 -year-old girl by a drug dealer, the robbery and killing of a retired minister which sparked a wave of gun law interest, a family who caught a man raping an 11-year-old family member, the torture and rape of a woman and execution of her boyfriend, and several shootings outside of nightclubs. 
We do not know if this level of serious crime and crime news is atypical of Baltimore or other cities. But salient levels of crime or at least disorder cues are a regrettable necessity of research on crime and, especially, fear of crime. Researchers in areas with less serious crime, crime news, or social and environmental disorder may not achieve the same results. It is important to note that these insights into the nature and possible impact of particular crimes and their news coverage come not from the quantitative portion of the news data, but from qualitative neighborhoodby-neighborhood news summaries, whose value should not be overlooked or underestimated.

Another important implication of these ecological assessment methods for theory, research, and action is their flexibility regarding content. As the present data demonstrate, all three methods lend themselves well to measuring community disorder. But there are many other ecological concepts that can be measured using these methods. More than half of the Block Environmental Inventory focuses on more positive or neutral characteristics of the environment not covered here, such as territoriality, beautification, and defensible space. Newspaper content analysis can, of course focus on any topic that is newsworthy and even ones that are not part of the "hard" news (e.g., violence in comics and movie advertising). For example, a methodology similar to the one presented here was used by the first author to evaluate both media and government treatment of different San Francisco neighborhoods (one wealthy, one poor) following the 1989 earthquake. With the advent of NEXIS and other news search services, the procedures for searching print media electronically have been made vastly more efficient.

Regarding surveys as an ecological method, the present and similar resident surveys have been aggregated to the block and neighborhood level to successfully measure all kinds of community social climate variables, such as citizen participation, neighboring, informal social control, sense of community, communitarianism, place attachments (Perkins et al., 1990), even aggregated anxiety and depression (Taylor \& Perkins, 1994). But surveys are still probably better for measuring individual psychological constructs than for assessing community ecologies. For the latter, community psychologists should explore alternative quantitative and qualitative methods that are more commensurate with both the community level of analysis and the multifaceted (social, physical, political, and economic) human environment, such as direct and participant observation, and content analysis of media and other recorded communication. 


\section{APPENDIX A}

The instrument also includes many items not used in the present analyses. For example, "territorial markers" (e.g., garden, yard decoration, other "personalizations," crime prevention signs) convey control over an area and a separation between one's self, family, or community and "outsiders," and are related to residents' perceptions of safety (Taylor et al., 1984), to their perception of less community disorder and crime problems (Perkins et al,, 1992), and to more or less police reports of crime, depending upon the type of marker (Perkins et al., 1993). "Defensible space" describes features of the built environment, such as building size, street layout, width and lighting, sight lines for passive surveillance, and barriers to entry, that have been associated with modest, but real, reductions in crime (Perkins et al., 1993) and fear (Newman \& Franck, 1982; Taylor et al., 1984). Other studies have found defensible space features to have a limited influence on the residential social climate and thus fear levels (Merry, 1981) or to have some positive and some negative effects on perceived crime and disorder (Perkins et al., 1992). Nonresidential land use (corner stores, schools, etc.) has been found to encourage reported crime (Perkins et al., 1993) and observed incivilities (Taylor, Koons, Kurtz, Greene, \& Perkins, 1995). Instructions and the latest version of the BEI may be obtained from the first author.

\section{APPENDIX B}

Assume we have a model where the outcome $(Y)$ is fear of crime, and the individuallevel predictor is perceived physical deterioration. Assume we have a group level predictor, in the form of a dummy variable $W$, indicating a high or low score on observed signs of incivility. HLM provides an individual-level model (Level 1), and a group-level (Level II) model. The Level I model would be

$$
Y_{i j}=\beta_{0 j}+\beta_{1 j}\left(X_{i j}-X_{. j}\right)+r_{i j}
$$

where $Y_{i j}=$ score of individual $i$ in block $j$ on fear of crime, $\beta_{0 j}=$ unique $Y$-intercept for each $j$ th block, $\beta_{1 j}=$ unique slope for each $j$ th block, $\left(X_{i j}-X_{. j}\right)=$ each individual's perceived physical deterioration, after subtracting the average perceived physical deterioration in his/her block, and $r_{i j}=$ the residual, unexplained portion of $Y$.

The model assumes (Bryk \& Raudenbush, 1992, p. 12) that: $r_{i j}$ is normally distributed, with homogeneous variance across blocks, and that the slopes $\left(\beta_{1 j}\right)$ and intercepts $\left(\beta_{0 j}\right)$ each have a bivariate normal distribution across blocks. A plausible hypothesis would be that those who perceive more deterioration will be more fearful.

The Level II model seeks to predict the block slopes and intercepts noted above. The two equations in the Level II model are as follows:

$$
\begin{aligned}
& \beta_{0 j}=\gamma_{00}+\gamma_{01} W_{j}+\mu_{0 j} \\
& \beta_{1 j}=\gamma_{10}+\gamma_{11} W_{j}+\mu_{1 j}
\end{aligned}
$$

where $\gamma_{00}=$ mean fear score in blocks where observed incivilities rates are below the median (i.e., the intercept in these blocks); $\gamma_{01}=$ mean fear difference between blocks with observed incivilities levels below the median and those above the median; $\gamma 10=$ average slope of fear 
on perceived physical deterioration in blocks where observed incivilitics are below the median; $\gamma_{11}=$ average difference in the slope of fear on perceived physical deterioration in blocks where observed incivilities are below the median versus those where it is above the median; $\mu_{0 j}=$ unique effect of block $j$ on average level of fear in a block after controlling for the differences on the outcome between low and high observed incivilities blocks (It captures between-block effects on the $Y$-intercept due to block differences other than observed incivilities.); and $\mu_{1 j}=$ unique effect of Block $j$ on the slope of fear on perceived physical deterioration after controlling for the effects that observed incivilities have on the slope. (It captures between block differences on the slope duc to block differences other than incivilities).

Substituting from Equation 2 and Equation 3 back into Equation 1, we derive the full combined model, that can be estimated with HLM using iterative maximum likelihood procedures.

$$
Y_{i j}=\gamma_{00}+\gamma_{01} W_{j}+\gamma_{10}\left(X_{i j}-X_{. j}\right)+\gamma_{11}\left(X_{i j}-X_{. j}\right)+\mu_{0 j}+\mu_{11}\left(X_{i j}-X_{. j}\right)+r_{i j}
$$

In the current study, however, we have fixed the slope of Level I predictors, not allowing them to vary across blocks. We did this because we did not have enough cases per block. Raudenbush (1988) advises having at least 20 cases per group to efficiently model variations in slopes, which represent, in effect, interactions between the individual predictor and the group predictor. Further, in this study we do not have theoretical rationales for allowing specific slopes to vary. Therefore, we are assessing a reduced model, setting the Level II model of $\beta_{1 j}=\gamma_{10}$, so the combined model is:

$$
Y_{i j}=\gamma_{00}+\gamma_{01} W_{j}+\gamma_{10}\left(X_{i j}-X . j\right)+\mu\left(0 j+r_{i j}\right.
$$

and $\gamma 10$ is the slope of perceived physical deterioration on all blocks.

\section{REFERENCES}

Babbie, E. (1995). The practice of social research (7th ed). Belmont, CA: Wadsworth.

Balkin, S. (1979). Victimization rates, safety, and fear of crime. Social Problems, 26, 343-350.

Bryk, A. S., \& Raudenbush, S. W. (1987). Application of hierarchical linear models to assessing change. Psychological Bulletin, 10I, 147-158.

Bryk, A. S., \& Raudenbush, S. W. (1992). Hierarchical linear models: Applications and data analysis methods. Newbury Park, CA: Sage.

Bryk, A. S., \& Thum, Y. M. (1989). The effects of high school on dropping out: An exploratory investigation. American Educational Research Journal, 26, 353-384.

Clarke, R., Ekblom, P., Hough, M., \& Mayhew, P. (1985). Elderly victims of crime and exposure to risk. Howard Journal of Criminal Justice, 24, 1-9.

Covington, J., \& Taylor, R. B. (1991). Fear of crime in urban residential neighborhoods; Implications of between- and within-neighborhood sources for current models. Sociological Quarterly, 32, 231-249.

Crenson, M. (1983). Neighborhood politics. Cambridge, MA: Harvard University Press.

Ditton, J., \& Duffy, J. (1983). Bias in the newspaper reporting of crime news. British Journal of Criminology, 23, 159-165.

Dubow, F., McCabe, E., \& Kaplan, G. (1979). Reactions to crime: A critical review of the literature. Washington, DC: U.S. Government Printing Office.

Ferraro, K. F. (1994). Fear of crime: Interpreting victimization risk. Albany: State University of New York Press. 
Ferraro, K., \& LaGrange, R. (1987). The measurement of fear of crime. Sociological Inquin, $57,70-101$.

Garofalo, J., \& Laub, J. (1978). The fear of crime: Broadening our perspective. Victimology, 3, 242-253.

Gomme, I. M. (1988). The role of experience in the production of fear of crime: A test of a causal model. Canadian Journal of Criminology, 30, 67-76.

Goodman, A. C., \& Taylor, R. B. (1983). The Baltimore Neighborhood Factbook. Baltimore, MD: The Johns Hopkins University, Center for Metropolitan Planning and Research.

Greenberg, S. W., Rohe, W. M., \& Williams, J. (1982). Safe and secure neighborhoods: Physical characteristics and informal territorial control in high and low crime neighborhoods. Washington, DC: U.S. Department of Justice.

Greenc, J. R., \& Taylor, R. B. (1988). Community-based policing and foot patrol: Issues of theory and evaluation. In J. R. Greene \& S. D. Mastrofski (Eds.), Community policing: Rhetoric or reality? (pp. 195-224). New York: Praeger.

Hauser, P. M. (1974). Contextual analysis revisited. Sociological Methods and Research, 2, 365-375.

Hope, T., \& Hough, M. (1988). Area, crime, and incivility: A profile from the British Crime Survey. In T. Hope \& M. Shaw (Eds.), Communities and crime reduction (pp. 30-47). London: Her Majesty's Stationery Office.

Hunter, A. (1978, November). Symbols of incivility. Paper presented at the Annual Meeting of the American Society of Criminology, Dallas, TX.

Jaehnig, W. B., Weaver, D. H., \& Fico, F. (1981). Reporting crime and fearing crime in three communities. Joumal of Communication, 31, 88-96.

Kenny, D. A., \& Lavoie, L. (1985). Separating individual and group effects. Journal of Personality and Social Psychology, 48, 339-348.

Kurtz, E., \& Taylor, R. B. (1995). Fear of crime: Testing interactions between individual and context. Unpublished manuscript, Department of Criminal Justice, Temple University.

LaGrange, R. L., \& Ferraro, K. F. (1989). Assessing age and gender differences in perceived risk and fear of crime. Criminology, 27, 697-719.

LaGrange, R. L., Ferraro, K. F., \& Supancic, M. (1992). Perceived risk and fear of crime: Role of social and physical incivilities. Joumal of Research in Crime and Delinquency, 29, 311-334.

Lawton, M. P., \& Yaffe, S. (1980). Victimization and fear of crime in elderly public housing tenants. Journal of Gerontology, 35, 768-779.

Lewis, D. A., \& Maxfield, M. (1980). Fear in the neighborhoods: An investigation of the impact of crime. Joumal of Research in Crime and Delinquency, 17, 160-189.

Lewis, D. A., \& Riger, S. (1986). Crime as stress: On the internalization of a social problem. In E. Seidman \& J. Rappaport (Eds.), Redefining social problems. New York: Plenum Press.

Lewis, D. A., \& Salem, G. (1985). Fear of crime: Incivility and the production of a social problem. New Brunswick, NJ: Transaction.

Liska, A. E., \& Baccaglini, W. (1990). Feeling safe by comparison: Crime in the newspapers. Social Problems, 37, 360-374.

Liska, A. E., Sanchirico, A., \& Reed, M. D. (1988). Fear of crime and constrained behavior: Estimating a reciprocal effects model. Sacial Forces, 66, 827-837.

Maxfield, M. G. (1987). Incivilities and fear of crime in England and Wales and the United States: A comparative analysis. Paper presented at the Annual Meeting of the American Society of Criminology, Montreal.

Melnicoe, S. (Ed.). (1987). Special Issue: Fear of Crime. Crime and Delinquency, 33.

Merry, S. E. (1981). Urban danger: Life in a neighborhood of strangers. Philadelphia: Temple University Press.

Mulvey, A., Turro, G., Cutter, T., \& Pash, J. (1995). Crime, communities and qualities of lives: Women and men in Lowell, 1982-1994. Paper presented at the Biennial Conference on Community Research and Action, Chicago.

Newman, O., \& Franck, K. (1982). The effects of building size on personal crime and fear of crime. Population and Environment, 5, 203-220. 
Norris, F. H., \& Kaniasty, K. (1991). The psychological experience of crime: A test of the mediating role of beliefs in explaining the distress of victims. Joumal of Social and Clinical Psychology, 10, 239-261.

Norris, F. H., \& Kaniasty, K. (1992). A longitudinal study of the effects of various crime prevention strategies on criminal victimization, fear of crime, and psychological distress. American Journal of Community Psychology, 20, 625-648.

O'Brien, R. M. (1985). Crime and victimization data. Beverly Hills: Sage.

O'Keefe, G. J., \& Reid-Nash, K. (1987). Crime news and real-world blues: The effects of the media on social reality. Communication Research, 14, 147-163.

Ortega, S. T., \& Myles, J. L. (1987). Race and gender effects on fear of crime: An interactive model with age. Criminology, 25, 133-152.

Pawson, E., \& Banks, G. (1991). Rape and fear of violence in Christchurch. Community Mental Health in New Zealand, 6, 16-33.

Perkins, D. D., Florin, P., Rich, R. C., Wandersman, A., \& Chavis, D. M. (1990). Participation and the social and physical environment of residential blocks: Crime and community context. American Journal of Community Psychology, 18, 83-115.

Perkins, D. D., Meeks, J. W., \& Taylor, R. B. (1992). The physical environment of street blocks and resident perceptions of crime and disorder: Implications for theory and measurement. Joumal of Environmental Psychology, 12, 21-34.

Perkins, D. D., Wandersman, A., Rich, R. C., \& Taylor, R. B. (1993). The physical environment of street crime: Defensible space, territoriality and incivilities. Joumal of Environmental Psychology, 13, 29-49.

Raudenbush, S. W. (1988). Educational applications of hierarchical linear models: A review. Journal of Educational Statistics, 13, 85-116.

Raudenbush, S. W., \& Chan, W. (1992). Growth curve analysis in accelerate longitudinal designs. Journal of Research in Crime and Delinquency, 29, 387-411.

Raudenbush, S. W., \& Chan, W. (1993). Application of a Hierarchical Linear Model to the study of adolescent deviance in an overlapping cohort design. Joumal of Consulting and Clinical Psychology, 61, 941-951.

Riger, S., Gordon, M., \& LeBailly, R. (1981). Community ties and urbanites' fear of crime: An ecological investigation. American Journal of Community Psychology, 9, 653-665.

Rosenbaum, D. P., Lewis, D. A., \& Grant, J. A. (1986). Neighborhood-based crime prevention: Assessing the efficacy of community organizing in Chicago. In D. Rosenbaum (Ed.), Community Crime Prevention: Does it work? (pp. 109-133). Beverly Hills: Sage.

Sampson, R. J. (1987). Urban black violence: The effect of male joblessness and family disruption. American Journal of Sociology, 93, 348-382.

Skogan, W. (1990). Disorder and decline. New York: Free Press.

Skogan, W., Cook, F., Antunes, G., \& Cook, T. D. (1978). Criminal victimization of the elderly: The physical and economic consequences. Gerontologist, I8, 339-349.

Skogan, W., \& Maxfield, M. (1981). Coping with crime: Individual and neighborhood reactions. Beverly Hills: Sage.

Smith, S. J. (1984). Crime in the news. British Journal of Criminology, 24, 289-295.

Sparks, G. G., \& Ogles, R. M. (1990). The difference between fear of victimization and the probability of being victimized: Implications for cultivation. Journal of Broadcasting and Electronic Media, 34, 351-358.

Steward, D., Perkins, D. D., \& Brown, B. B. (1995, June 15). Community social ties and fear of crime. Presented at the Biennial Conference on Community Research \& Action, Chicago.

Taylor, R. B. (1987). Toward an environmental psychology of disorder: Delinquency, crime, and fear of crime. In D. Stokols \& I. Altman (Eds.), Handbook of environmental psychology (Vol. 2, pp. 951-986). New York: Wiley.

Taylor, R. B. (1995, July). Responses to disorder in Minneapolis-St. Paul: Relative impacts of neighborhood structure, crime, and physical deterioration. Unpublished final report (94-IJ-CX-0018) to the National Institute of Justice. Department of Criminal Justice, Temple University. 
Taylor, R. B. (1996). Neighborhood responses to disorder and local attachments: The systemic model of attachment, social disorganization, and neighborhood use value. Sociological Forum, 11, 41-74.

Taylor, R. B., \& Covington, J. (1993). Community structural change and fear of crime. Social Problems, 40, 374-397.

Taylor, R. B., Gottfredson, S. D., \& Brower, S. (1984). Block crime and fear: Defensible space, local social ties, and territorial functioning. Journal of Crime and Delinquency, 21, 303-331.

Taylor, R. B., Gottfredson, S. D. \& Brower, S. D. (1985). Attachment to place: Discriminant validity, and impacts of disorder and diversity. American Journal of Community Psychology, $13,525-542$.

Taylor, R. B., \& Hale, M. (1986). Testing alternative models of fear of crime. Journal of Criminal Law and Criminology, 77, 151-189.

Taylor, R. B., Koons, B. A., Kurtz, E. M., Greene, J. R., \& Perkins, D. D. (1995). Street blocks with more nonresidential land use have more physical deterioration: Evidence from Baltimore and Philadelphia. Urban Affairs Review, 31, 120-136.

Taylor, R. B., \& Perkins, D. D. (1994). The impact of block-level fear and citizen participation on changes in anxiety and depression: A stress and coping framework. Unpublished manuscript.

Taylor, R. B., \& Shumaker, S. (1990). Local crime as a natural hazard: Implications for understanding the relationship between disorder and fear. American Journal of Community Psychology, 18, 619-641.

Taylor, R. B., Shumaker, S., \& Gottfredson, S. (1985). Neighborhood-level links between physical features and local sentiments. Journal of Architectural Planning and Research, 2, 261-275.

Tyler, T. R. (1984). Assessing the risk of crime victimization: The integration of personal victimization experience and socially transmitted information. Journal of Social Issues, 40, 27-38.

Williams, P., \& Dickinson, J. (1993). Fear of crime: Read all about it? The relationship between newspaper crime reporting and fear of crime. British Journal of Criminology, 33, 33-56.

Wilson, J. Q. (1975). Thinking about crime. New York: Basic Books.

Wilson, J. Q., \& Kelling, C. (1982, March). The police and neighborhood safety: Broken windows. Atlantic, 127, 29-38. 